\title{
MRI in Multiple Sclerosis: What's Inside the Toolbox?
}

\author{
Mohit Neema,* James Stankiewicz,* Ashish Arora,* Zachary D. Guss,* and Rohit Bakshi*` \\ Departments of *Neurology and ${ }^{\dagger}$ Radiology, Center for Neurological Imaging, Partners MS Center, Brigham and Women’s \\ Hospital, Harvard Medical School, Boston, Massachusetts 02115
}

\begin{abstract}
Summary: Magnetic resonance imaging (MRI) has played a central role in the diagnosis and management of multiple sclerosis (MS). In addition, MRI metrics have become key supportive outcome measures to explore drug efficacy in clinical trials. Conventional MRI measures have contributed to the understanding of MS pathophysiology at the macroscopic level yet have failed to provide a complete picture of underlying MS pathology. They also show relatively weak relationships to clinical status such as predictive strength for clinical progression. Advanced quantitative MRI measures such as magnetization transfer, spectroscopy, diffusion imaging, and relaxometry techniques are somewhat more specific and sensitive for un-
\end{abstract}

derlying pathology. These measures are particularly useful in revealing diffuse damage in cerebral white and gray matter and therefore may help resolve the dissociation between clinical and conventional MRI findings. In this article, we provide an overview of the array of tools available with brain and spinal cord MRI technology as it is applied to MS. We review the most recent data regarding the role of conventional and advanced MRI techniques in the assessment of MS. We focus on the most relevant pathologic and clinical correlation studies relevant to these measures. Key Words: Multiple sclerosis, MRI, MR spectroscopy, magnetization transfer, diffusion imaging, spinal cord, brain, iron.

\section{INTRODUCTION}

MRI has emerged as a powerful noninvasive tool to assist in the diagnosis and monitoring of multiple sclerosis (MS). In addition, MRI has emerged as a key supportive therapeutic outcome measure in MS-related clinical trials. ${ }^{1}$ It has also aided in the understanding of the pathophysiology of the disease.

The study of MRI in MS has been flourishing in the field of research in recent years. Studies examining the conventional MRI-based measures, including CNS atrophy and lesions (T2 hyperintense, T1 hypointense, and gadolinium [Gd] enhancing) have uncovered remarkable information in the last two decades. ${ }^{1,2}$ These measures have not only provided the basic framework for the clinical diagnosis and management of MS, but they have also shed light on the underlying mechanisms of MS disease processes and provided surrogate outcome measures for clinical trials. ${ }^{1}$ However, mounting evidence suggests that these measures lack the specificity required for analyzing the underlying pathology and fail to cap-

Address correspondence and reprint requests to: Rohit Bakshi, MD, Brigham \& Women's Hospital, Harvard Medical School, 77 Avenue Louis Pasteur, HIM 730, Boston, MA 02115. E-mail: rbakshi@bwh. harvard.edu. ture clinically-relevant diffuse occult disease affecting the cerebral white matter (WM) and gray matter (GM). Conventional lesion measures show generally weak correlations with clinical status as measured by the Expanded Disability Status Scale and are unreliable for predicting clinical progression. ${ }^{1-3}$ These shortcomings contribute to the clinical MRI paradox seen in research and clinical settings.

The limitations of conventional MRI surrogates have driven investigators to develop better measures, including those that capture diffuse destructive aspects of the disease occurring throughout the CNS. Years of research have yielded technological advances leading to the development of advanced MRI measures, such as magnetization transfer (MT), magnetic resonance spectroscopy (MRS), diffusion imaging, and relaxometric techniques that are relatively more specific and sensitive for underlying pathology. ${ }^{1}$ These encouraging techniques hold promise in the field of MS MRI research, but their relevance to clinical and investigational settings remains unproven.

In this article, we will provide an overview of the array of tools available with MRI technology as it is applied to brain and spinal cord imaging in patients with MS. We will focus on the recent developments that have unfolded in the field of conventional and advanced MRI. Due to 

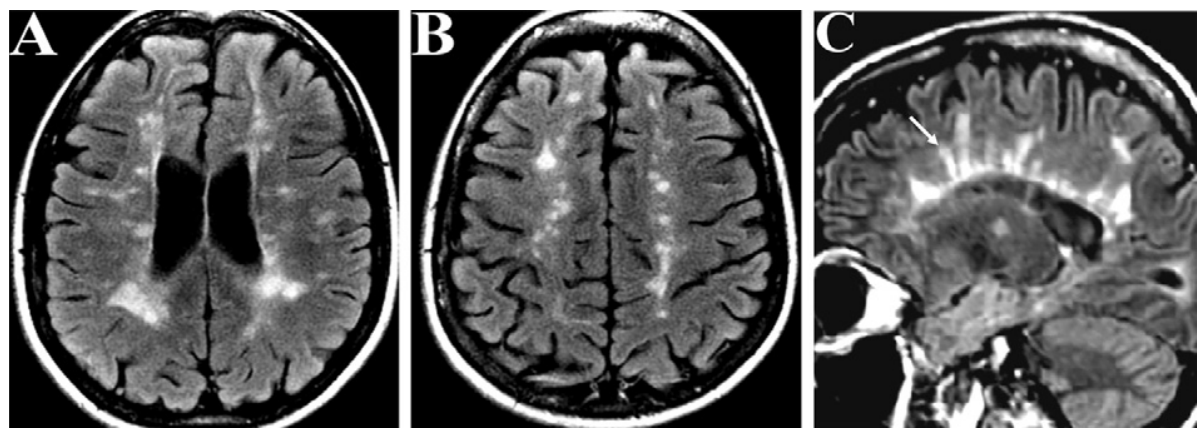

FIG. 1. Fluid-attenuated inversion-recovery images of a 43-year-old woman with relapsing-remitting multiple sclerosis (MS) (A-C). Note the typical hyperintense lesions, oval/ovoid in shape and seen in the periventricular white matter and juxtacortical gray-white junction. Several of the periventricular lesions directly contact the ventricular ependyma. In addition, most of the lesions are $5 \mathrm{~mm}$ or greater in diameter. The sagittal image (C) reveals "Dawson's fingers," characteristic of MS, believed to occur because of perivenular inflammation; the arrow indicates one of several "Dawson's fingers" seen on the sagittal image.

space limitations, we shall not include a review of optic nerve or functional brain imaging in patients with MS, which have been recently reviewed in this journal and elsewhere. $^{4-6}$

\section{T2-hyperintense lesions}

MS plaques on conventional proton-density and T2weighted brain images appear as bright areas and are often referred to as T2-hyperintense lesions (FIG. 1). Such lesions are typically oval to ovoid in shape and 5 $\mathrm{mm}$ or greater in diameter (FIG. 1). Hyperintensities in the brain are more common in the WM than GM on these conventional sequences. Lesions commonly affect the periventricular WM regions, the inner surface of the corpus callosum, the juxtacortical gray-white junction, the infratentorial brain regions, and the spinal cord (FIG. 1). In many patients, finger-like hyperintensities perpendicular to the lateral ventricles can be appreciated. These so-called "Dawson's fingers" are believed to reflect perivenular inflammation seen histologically in MS (FIG. 1). Some of the T2-hyperintense lesions may resolve and wane over time, as reviewed recently in this journal. ${ }^{7}$ However, most newly formed $\mathrm{T} 2$ lesions chronically persist as "footprints" of damage. T2-hyperintense lesions in patients with MS are nonspecific for the underlying pathology, which may include varying degrees of inflammation, demyelination, gliosis, edema, Wallerian degeneration, and axonal loss.

During the past few years, advanced techniques have been developed to increase the sensitivity in detecting MS-related demyelinating foci. These include fast or turbo spin-echo, ${ }^{8}$ fluid-attenuated inversion recovery (FLAIR) (FIGS. 1 and 2), ${ }^{9}$ and double inversion recovery (DIR). ${ }^{10}$ There are relative advantages and disadvantages to each. For example, conventional and fast spinecho T2-weighted images are relatively less sensitive than newer techniques in detecting periventricular and cortical-juxtacortical lesions. A full review of MRI detection of GM involvement has been recently published. ${ }^{11}$ Because FLAIR and DIR sequences suppress
CSF bright signal, they detect GM lesions with greater sensitivity (FIG. 2)..$^{9-13}$ On the other hand, FLAIR is relatively insensitive for identifying lesions in the posterior fossa and spinal cord due to flow-related artifacts. The advent of ultrahigh-field MRI (i.e., 3 Tesla [T] and higher) brings the promise of increased sensitivity for detecting MS lesions (e.g., see section on "Ultrahighfield strength MRI" as follows).

Brain T2 lesions in both cross-sectional and short-term longitudinal studies show generally weak correlations with clinical disability, as measured using the Expanded
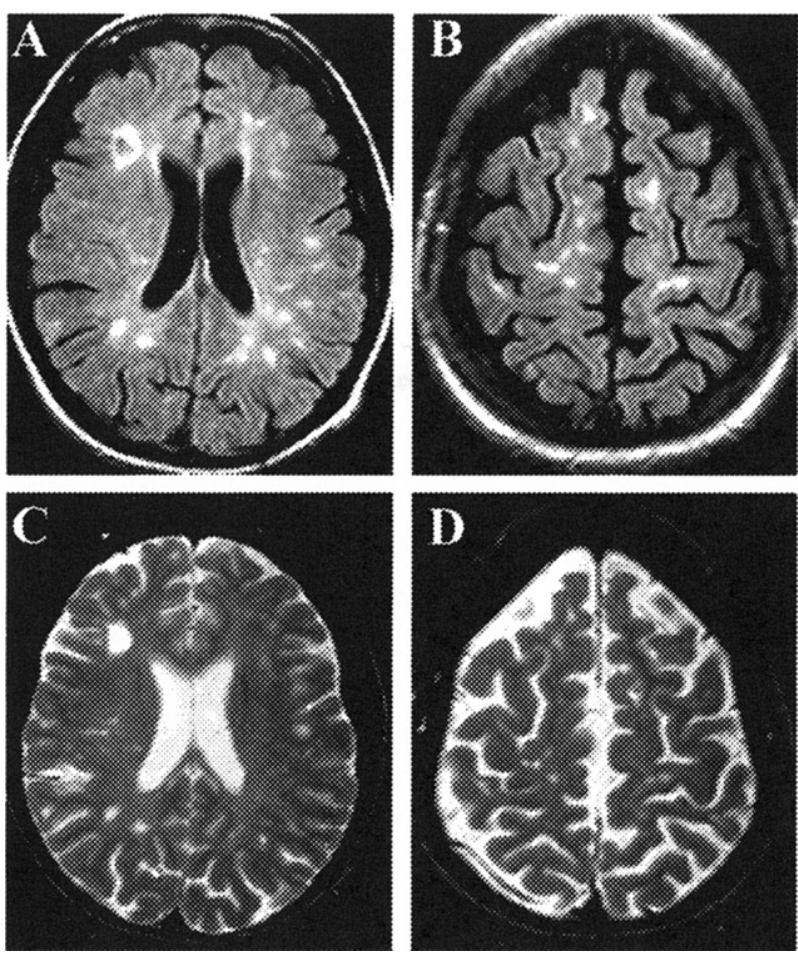

FIG. 2. Fluid-attenuated inversion-recovery images $(A, B)$ and spin-echo T2-weighted images (C, D) of a 34-year-old woman with relapsing-remitting multiple sclerosis. Note the improved conspicuousness of periventricular and cortical/juxtacortical lesions on the fluid-attenuated inversion recovery images compared to T2 images. 

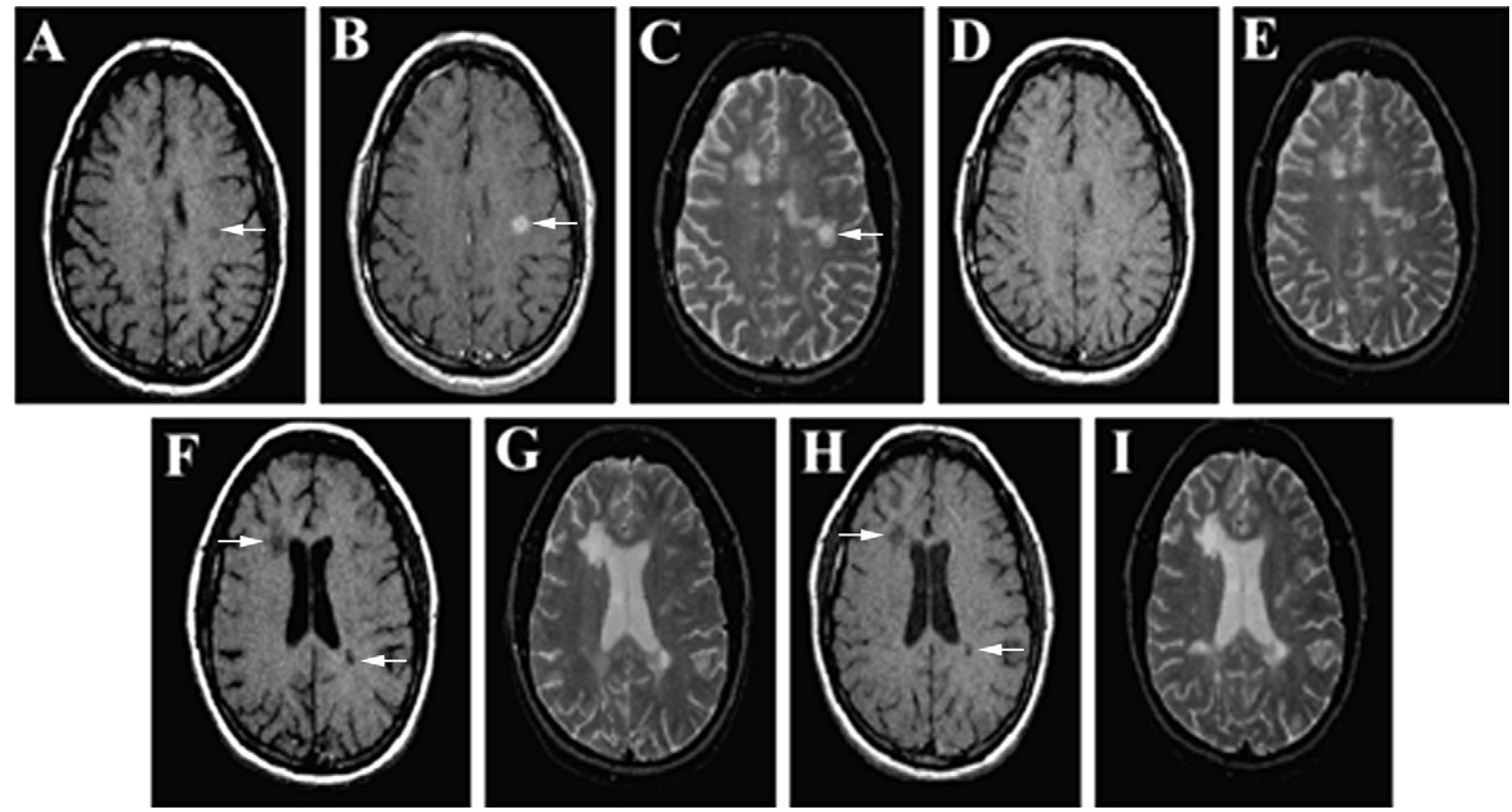

FIG. 3. Transient ( $A-E)$ and chronic $(F-I)$ hypointense lesions ("black holes") on noncontrast T1-weighted images (A, D, F, H) in a patient with relapsing-remitting multiple sclerosis (MS). Figure B is a post-contrast (gadolinium-enhanced) T1-weighted image. Figures C, E, G, and I are T2-weighted images. A newly formed T1 hypointensity is displayed on the baseline images (A-C, arrows) and resolved seven months later on the follow-up T1-weighted image (D) with a small residual lesion remaining on the T2-weighted image (E). The baseline images in the lower panel (F, G) are from the same patient as the upper panel and show two T1 hypointensities (arrows), which persisted on the follow-up scan performed eight months later (arrows) $(\mathrm{H}, \mathrm{I})$.

Disability Status Scale. ${ }^{3}$ This dissociation has been attributed to many factors, including the compensatory abilities of brain tissue, the limitations of the clinical rating scale, the failure of $\mathrm{T} 2$-weighted images to characterize diffuse disease, and the presence of spinal cord disease. However, the degree of T2-hyperintense lesions assumes clinical significance early in the disease course of MS and has a prognostic value in predicting conversion from a clinically isolated syndrome (CIS) to relapsing-remitting MS. ${ }^{14-17}$ Baseline cerebral T2-lesion volume (T2LV) combined with whole brain atrophy is a relatively strong predictor of short-term disability in patients with CIS and relapsing-remitting MS (RRMS). ${ }^{18}$ In a 13-year longitudinal study, baseline T2LV predicted the development of brain atrophy; moreover, the change in T2LV in the first two years predicted the long-term neurological and cognitive status. ${ }^{19}$

T2-based qualitative and quantitative measures have been used to monitor the therapeutic value of various drugs, as we have recently reviewed. ${ }^{1}$ All of the diseasemodifying agents approved by the Food and Drug Administration (FDA) have shown a significant benefit in limiting the progression of T2LV. However, one of the major limitations in using T2LV as a longitudinal surrogate measure is the plateauing relationship between $\mathrm{T} 2 \mathrm{LV}$ and disability, ${ }^{20}$ which reflects in part the engulfing of $\mathrm{T} 2$ lesions by the expanding CSF spaces in the midst of progressive brain atrophy and disease progression; this plateauing also probably reflects the role of diffuse occult disease in WM and GM that escapes detection with conventional MRI.

\section{T1 hypointense lesions}

A subset of T2 hyperintense MS lesions may appear hypointense on corresponding T1-weighted images (FIG. 3). These hypointensities (also called "black holes") are commonly seen in the supratentorial brain regions and rarely seen in the posterior fossa and spinal cord. A T1-hypointense lesion most commonly develops initially as a Gd-enhancing lesion and has about a 50-50 chance of being either transient (i.e., lasting 6-12 months) or being permanent (FIG. 3). The age and degree of T1 hypointensity reflects the underlying pathology in T1hypointense lesions. Those that show profound hypointensity and permanence primarily reflect irreversible tissue destruction (i.e., irreversible demyelination and axonal loss) whereas those that are transient reflect edema and demyelination with subsequent remyelination. ${ }^{21,22}$ Not surprisingly, chronic persistent T1-hypointense lesions are associated to a moderate degree with global brain atrophy. ${ }^{23,24}$

However, there are technical considerations to be kept in mind with regard to T1-hypointense lesions. The degree of $\mathrm{T} 1$ hypointensity in lesions depends on the MRI 

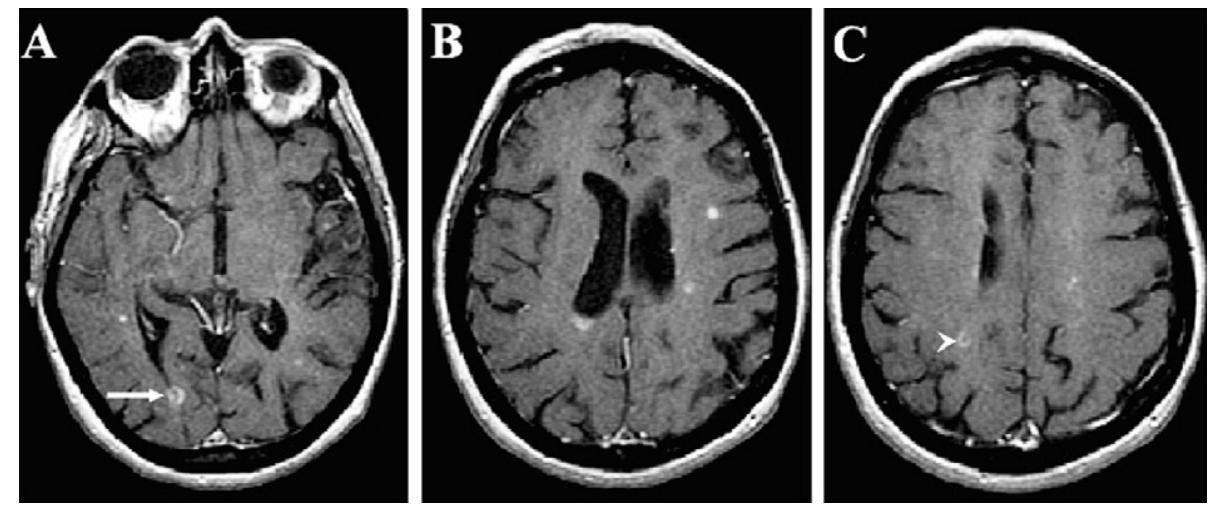

FIG. 4. Post-gadolinium $T 1$-weighted spin-echo images (A-C) of a 54-year-old woman with relapsing-remitting multiple sclerosis (MS). The patient has open-ring lesions (A, C: arrow and arrowhead), typical of MS, as well as homogenously enhancing lesions.

pulse sequence, which may explain the discrepancies in the results reported among investigators. Furthermore, most previous studies of T1-hypointense lesion volume have been based on manual or semiautomated identification of lesions. ${ }^{25,26}$ These methods have limited efficiency and reproducibility, particularly with regard to assessing large data sets in multicenter clinical trial settings or comparing data across analysis centers. Recently, Datta et al. ${ }^{27}$ developed an automated method based on fuzzy connectedness principles for identification and quantification of T1-hypointense lesions. This method holds promise as it involves minimal operator interaction.

Both cross-sectional and longitudinal studies indicate a moderate to strong correlation between whole brain T1hypointense lesion load and neurological impairment. ${ }^{3,23,28}$ Patients with secondary progressive (SP) MS and primary progressive (PP) MS typically show more T1-hypointense lesions as a proportion of T2-hyperintense lesions than patients with RRMS. ${ }^{29}$ Analyses that incorporate T1-hypointense lesion volume with conventional T2 measures correlate better with neurologic impairment than T2 measures alone. ${ }^{3}$ In addition, patients with SPMS tend to show stronger T1-hypointense lesionclinical correlation than patients with RRMS. ${ }^{21,28}$

The amount and duration of $\mathrm{Gd}$ enhancement at baseline may determine the final course of T1-hypointense lesion development. ${ }^{30}$ However, due to the irregular nature of T1-hypointense lesion evolution, this predictive power is limited. Advanced MRI techniques, such as magnetization transfer (MT) imaging, better predict the conversion from acute to chronic T1-hypointense lesions. ${ }^{31}$

Analyses of global T1-hypointense lesion volume change, or the effect on the evolution of newly formed individual T1-hypointense lesions, have emerged as supportive outcome measures in MS related neurotherapeutic trials, as recently reviewed. ${ }^{1}$

\section{Blood-brain barrier compromise}

The development and evolution of an MS lesion is characterized by disruption of the blood-brain barrier and migration of leukocytes into the brain parenchyma. With MRI, this process can be captured in the form of leakage of intravenously administered Gd contrast. ${ }^{32} \mathrm{Gd}$ enhancement is best observed with spin-echo T1-weighted images. The sensitivity in detecting such lesions can be enhanced with technical improvements, such as delivering an off-resonance MT pulse, ${ }^{33}$ delaying the scanning by 5 minutes or more after Gd injection, ${ }^{33,34}$ or increasing the Gd dose $^{35}$ with ultrahigh field MRI (e.g., see section on "Ultrahigh-field strength MRI" as follows) ${ }^{35}$ or with improved post-processing methods. ${ }^{36}$

Gd enhancement usually precedes or accompanies new T2-hyperintense lesion formation, but disappears after an average of three to six weeks. ${ }^{37}$ Therefore, such enhancement is not seen with the appearance of new T2 lesions unless frequent imaging is performed. Gd-enhancing lesions can be categorized into multiple morphologic types, such as concentric ring, open ring, heterogeneous, and homogeneous enhancement (FIG. 4). Homogeneousenhancing lesions are the most commonly seen form in patients with MS. Open ring enhancement is fairly specific for MS. ${ }^{38}$ Ring-enhancing lesions show higher levels of tissue destruction ${ }^{39,40}$ than homogeneously-enhancing lesions and thus tend to resolve more slowly. Moreover, ring-enhancing lesions are at high risk for conversion to chronic T1-hypointense lesions ${ }^{41}$ and predict global brain parenchymal loss. ${ }^{42}$

Whereas prior Gd-enhanced MRI studies focused mostly on analyzing visible enhancing lesions, emerging studies have also begun to analyze subtle blood-brain barrier disruptions that are usually missed on visual inspection. ${ }^{43,44}$ Using quantitative T1-relaxometry analysis, Soon et al. ${ }^{44}$ recently demonstrated that subtle bloodbrain barrier disruption can occur in nonenhancing 
lesions and is seen in all clinical phenotypes and across various lesion morphologies.

The clinical MRI paradox with regard to conventional imaging manifests with Gd-enhancing lesions in several ways. Enhancing lesions often are clinically silent and therefore show a poor correlation with current clinical status. ${ }^{45,46}$ Such lesions are unreliable predictors of progressive disability. ${ }^{47}$ In addition, patients with RRMS frequently show a higher frequency of enhancement than patients with progressive forms of MS. Nevertheless, their presence increases the risk of continuous disease activity ${ }^{48}$ and the short-term appearance of clinical relapses. ${ }^{46,48,49}$

All of the disease-modifying agents that are approved by the FDA for the treatment of MS show a significant effect on limiting Gd enhancement as recently reviewed. ${ }^{1}$ Furthermore, a drug that exacerbates MS may be detected early by observing worsening Gd enhancement.

Studies from the experimental autoimmune encephalomyelitis model, an animal model of MS, indicate that macrophage infiltration into the brain parenchyma can be tracked using novel contrast agents, relying on the MRI detection of ultra small-particle iron oxides (USPIOs). USPIOs accumulate in phagocytic macrophages and thus may provide more precise information about the pathophysiologic cascade of the inflammatory events in vivo. ${ }^{50,51}$ In a study involving 10 patients with MS in acute relapses, Dousset et al. ${ }^{52}$ found 33 USPIO-enhanced lesions in 9 of the 10 patients compared to 55 Gd-enhancing lesions detected in 7 of the 10 patients. Importantly, 2 USPIO-enhanced MS lesions showed no Gd enhancement; 24 lesions showed only Gd enhancement, and 31 lesions showed enhancement with both contrast agents. The investigators suggested that macrophage infiltration is mainly associated with blood-brain barrier disruption; however, it can be spatially independent, contributing to the discrepancy observed in the uptake of both contrast agents. Further studies on the significance of cell-specific agents such as USPIO will be potentially important for understanding the evolution of MS lesions and the role of macrophages/microglia.

\section{Diagnostic criteria}

Both T2-hyperintense and Gd-enhancing lesions are used in the formal diagnosis of MS. The International Panel criteria were revolutionary in allowing a characteristic change (for the first time) in MRI findings to demonstrate dissemination in time that could substitute for a second clinical attack. ${ }^{53}$ A panel convened to update the criteria expanded it for dissemination in time. ${ }^{54}$ Specifically, a new T2 lesion demonstrated at least one month (rather than three months) after the initial attack can be used to establish dissemination in time. They also expanded the use of spinal cord lesions in the MRI criteria for dissemination in space. With the revised criteria, a T2-hyperintense spinal cord lesion can be used as a substitute for an infratentorial brain lesion, whereas a Gd-enhancing spinal cord lesion can substitute for a Gdenhancing brain lesion. It is likely that future improvements in MRI diagnostic criteria will include a consideration of ultrahigh-field imaging, diffuse occult disease, and GM involvement once the technologies for these assessments reach maturity.

\section{MRS}

MRS is a technique that derives an MRI signal from various metabolites. The reader is referred to two recent reviews in this journal that include a discussion of the technical aspects of MRS. ${ }^{5,56}$ Proton MRS studies have revealed that myriad brain metabolite concentrations including $\mathrm{N}$-acetylaspartate (NAA), choline (Cho), lactate (Lac), lipids, myoinositol (mI), and glutamate/glutamine are altered in patients with MS and undergo longitudinal change. ${ }^{55,57,58}$ Individual metabolites are believed to reflect specific underlying pathologies. For example, in patients with MS, decreased NAA is proposed as a marker for the loss of axonal/neuronal integrity, increased Cho indicates membrane turnover such as that seen with demyelination/remyelination, increased Lac indicates energy failure, increased lipid represents myelin breakdown or necrosis, and increased $\mathrm{mI}$ reflects gliosis.

MRS provides insight into the sequence of events that occur during the development of MS lesions. Overt, newly formed Gd-enhancing lesions often show elevated Cho, Lac, creatinine $(\mathrm{Cr}), \mathrm{mI}$, and lipids and reduced NAA. ${ }^{59,60}$ In addition, glutamate levels, which can be resolved from the glutamine peak with $3 \mathrm{~T}$ MRI, have also been proposed to significantly rise in lesions, suggesting a link between excitatory amino acids and axonal damage perhaps due to excitotoxicity. ${ }^{61}$ With lesion evolution, the extent of recovery of these metabolites is highly variable. In most lesions, $\mathrm{Lac}, \mathrm{Cho}, \mathrm{Cr}$, and lipids return to normal after an initial surge suggesting resolution of edema and remyelination, with reversible metabolic changes. ${ }^{58,62,63}$ However, NAA tends to remain persistently low or shows only partial recovery indicating irreversible axonal injury/loss. ${ }^{62}$

One of the major uses of MRS is the ability to detect microscopic damage in WM and GM areas that are free of overt lesions on conventional MRI scans, such as the so-called "normal appearing white matter" (NAWM). ${ }^{60,63,64}$ In NAWM, MRS shows decreased NAA, which likely reflects a loss of axonal integrity (either axonal injury, axonal loss, or both)..$^{59,60,65} \mathrm{In}$ addition, MRS may detect elevated Cho, mI, and lipids in NAWM. Such "pre-lesional" changes may appear months before the development of T2-hyperintense 

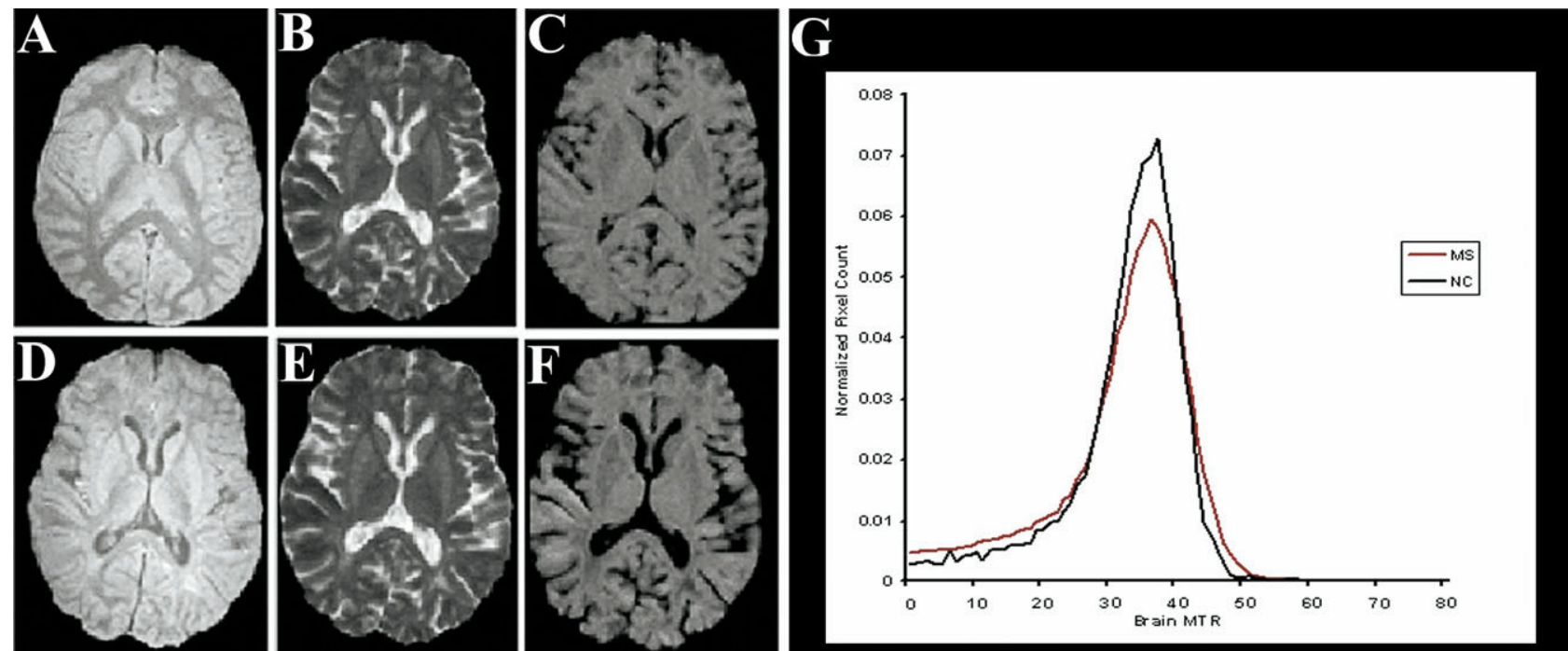

FIG. 5. Axial magnetization transfer (MT) images and maps of a healthy control in the fourth decade (A-C) and an age-matched patient with relapsing-remitting multiple sclerosis (MS) (D-F). The spin-echo proton density-weighted MT source images are shown with (B, E) and without $(A, D)$ the on-resonance MT saturation radio frequency pulse. The intra-subject source images are co-registered and MT ratio (MTR) maps are generated (C, F) per our previously described method. ${ }^{100}$ Whole-brain MTR histograms $(\mathrm{G})$ are then derived from all nonbackground pixels in the MTR images (C, F). Note the patient with MS (G, red line) has a lower histogram peak height than the normal control (G, black line), despite the fact that the patient with MS is early in the course of the disease, with only mild physical disability (Expanded Disability Status Scale score of 1.5) with a disease duration of only two years. (NC = normal controls.)

lesions, ${ }^{62}$ indicating that intrinsic brain parenchymal changes may precede the development of overt Gdenhancement. At the earliest clinical stage of MS (in patients with CIS), $\mathrm{mI}$ is elevated in NAWM, whereas NAA, Cho, and lipid/Lac remain normal. ${ }^{66}$ There is growing interest in GM involvement in MS, which includes both demyelinating lesions and neuronal loss. ${ }^{11}$ GM changes can be detected by MRS, such as decreased NAA and lipid/Lac peaks. ${ }^{67-70}$

Various studies have looked at the clinical relevance of MRS measures in patients with MS. Such measures show relatively stronger correlations with clinical measures of disability (i.e., cognitive dysfunction and physical disability) than do conventional MRI measures. ${ }^{71-78}$ Longitudinal studies suggest that MRS measures hold promise in predicting the development of disability. ${ }^{71-72}$ MRS is just beginning to be applied to the study of the spinal cord in patients with MS (e.g., see section on "Spinal cord imaging" as follows for details).

Several of the disease-modifying therapies approved by the FDA have shown a significant effect on limiting the progression of MRS derived metrics, such as NAA, including the interferons and glatiramer acetate, as recently reviewed. ${ }^{1,57}$ However, results have been variable and confined to nonrandomized small studies. In addition, the reproducibility and inter-institutional standardization of MRS data present technical challenges that are currently under investigation. ${ }^{65}$ It remains unknown if MRS will provide a reliable and sensitive tool to monitor therapeutic effects in large multi-center phase II/III trials.

\section{Magnetization transfer imaging}

Magnetization transfer imaging (MTI) is emerging as a sensitive MRI method to detect disease activity and monitor disease progression in MS. The reader is referred to recent reviews, including one from this journal, which include a discussion of the technical aspects of MTI. ${ }^{79,80}$ Injury to CNS structures can cause a decrease in exchange of tissue mobile protons. This abnormality can be captured on MTI as a decreased magnetization transfer ratio (MTR) (FIG. 5). Decreased MTR is believed to primarily reflect demyelination and axonal loss, but it is also probably affected to some extent by inflammation, gliosis, and edema.

Overt MS lesions seen on conventional MRI scans are characterized by decreased MTR compared to normal WM areas. T2-hyperintense lesions that show hypointensity on corresponding T1-weighted images usually have more profound reduction in MTR than lesions with T1 isointensity. ${ }^{81,82}$ The profound and persistent loss of MTR in lesions is more closely linked to physical disability than lesions with relative preservation of MTR. ${ }^{80}$ For example, studies have found lower lesion MTR in progressive patients than in patients with early disease. ${ }^{83}$ Similarly, patients with RRMS show lower MTR in established lesions than patients with benign MS and CIS. ${ }^{84,85}$ Newly appearing Gd-enhancing lesions tend to have initially low MTR, which in time can either return to normal or remain low after the enhancement has resolved. ${ }^{86-88}$ The degree of MTR loss in Gd-enhancing lesions at 
baseline predicts the risk of conversion to chronic T1-hypointense lesions; lesions with only mild or moderate compromise in MTR at the time of enhancement are most likely to revert to $\mathrm{T} 1$ isointensity. ${ }^{31}$ Profoundly reduced MTR indicates a chronic inactive lesion with axonal swelling, axonal loss, and severe demyelination. ${ }^{22,89,90}$

MTI is also capable of revealing microscopic damage in normal appearing brain tissue that is free from any visible lesions on conventional MRI scans. ${ }^{86,91,92}$ Many studies have demonstrated MTR changes in NAWM in all the MS phenotypic subtypes, ${ }^{91-93}$ including patients very early in the course of the disease (FIG. 5). A recent study found that the NAWM adjacent to T2 lesions has significantly lower MTR than regions distant to lesions, suggesting that the extent of demyelination in MS lesions is greater than that shown by conventional MRI. ${ }^{94}$ MTI can also detect pre-lesional pathology that precedes the appearance of overt Gd-enhancing lesions by several months. ${ }^{88,95}$ Furthermore, MTI has been helpful in improving the ability to detect damage in GM, including the cerebral cortex and subcortical nuclei. ${ }^{93,96,97}$ These changes may appear very early in the course of the disease, ${ }^{93,96-99}$ and they are more severe in progressive patients. ${ }^{100} \mathrm{Con}$ versely, the distribution of GM MTR changes reported across various studies is not consistent. One study found that even though MTR could detect damage in NAWM, it could not detect GM changes in a cohort of patients with MS as compared to normal controls. ${ }^{100}$

MTR changes in NAWM and GM in patients with MS show moderate to strong correlations with physical disability ${ }^{9,101-104}$ and cognitive dysfunction. ${ }^{105-108}$ Data from various longitudinal studies suggest that MTR may be a sensitive marker for predicting subsequent disability and disease progression. ${ }^{103,104,109}$ MTI is beginning to be applied to the study of the spinal cord in patients with MS (e.g., see section on "Spinal cord imaging" as follows).

Several of the disease modifying therapies approved by the FDA have shown an effect on limiting the progression of MTR-derived metrics or on promoting their recovery after initial decreases, including the interferons and glatiramer acetate, as recently reviewed. ${ }^{1,79}$ However, results have been variable and have been mostly confined to nonrandomized small studies. The technical challenges posed by MTI include inter-institutional standardization of protocols and data obtained. Thus, it remains to be determined if MTI will provide a reliable and sensitive tool to monitor therapeutic effects in large multi-center phase II/III trials.

\section{Diffusion imaging}

Because axons are the major component of the pathophysiology of MS, any technique that sensitively captures fiber architecture should prove useful in under- standing the disease. As a result, MRI diffusion imaging, including diffusion-weighted imaging or the more sophisticated diffusion tensor imaging (DTI) are of growing interest as tools to better define MS-related tissue damage and understand disease pathophysiology. The reader is referred to recent reviews, including one from this journal that includes a discussion of the technical aspects of diffusion imaging. ${ }^{110,111}$ Diffusion imaging is based on the detection of alterations in the direction, randomness, and velocity of water movement in tissue. DTI may be used to map the three-dimensional diffusion of water and describe the magnitude, degree, and orientation of diffusion anisotropy. In patients with MS, both demyelination and loss of axonal integrity in WM cause increased water diffusion, which can be measured by increased mean diffusivity (also known as apparent diffusion coefficient $[\mathrm{ADC}]$ ) or decreased fractional anisotropy (FA). However, it should be kept in mind that diffusion imaging metrics are nonspecific and may also reflect gliosis, edema, and inflammation..$^{40,112-114}$ Recent technological advances in diffusion imaging allow the derivation of radial versus axial diffusivity measures, which are proposed to provide additional specificity for myelin versus axonal integrity, respectively. ${ }^{110}$

WM lesions in patients with MS are generally characterized by increased ADC and decreased FA. ${ }^{40,114,115}$ In a small subset of lesions, particularly those with ring-like $\mathrm{Gd}$ enhancement, ADC may be decreased in the acute phase. ${ }^{40}$ T2-hyperintense lesions that appear as hypointense lesions on corresponding T1-weighted images show higher ADC than those that are $\mathrm{T} 1$ isointense; the profound increase in $\mathrm{ADC}$ of T1-hypointense lesions most likely reflects severe axonal damage and myelin loss. ${ }^{40,113,114}$ Schmierer et al. ${ }^{116}$ in a postmortem study of progressive MS subjects with chronic WM lesions reported that mean diffusivity and fractional anisotropy correlated strongly with the myelin content and less strongly with axonal count. Lesion changes seen with diffusion imaging in patients with MS probably also reflect inflammation, edema, and, to a lesser extent, gliosis.

Diffusion imaging can also detect tissue damage in areas free of overt lesions on conventional MRI scans in patients with MS including the NAWM. ${ }^{112-115,117-119}$ Such involvement can be exquisitely detected with DTI, including tract-specific alterations. ${ }^{117,120-124}$ Combining MRI-based perfusion and diffusion imaging, one recent study found that hypoperfusion in the callosal NAWM was correlated with decreasing MD, prompting the authors to hypothesize that ischemic damage may play a role in Wallerian degeneration. ${ }^{123}$ In patients with MS, diffusion imaging has uncovered significant GM changes, ${ }^{118,119,125,126}$ which are more readily detected than diffusion-related WM abnormalities. ${ }^{126}$

The advances in diffusion imaging techniques have led to a growing interest in how these metrics correlate with 

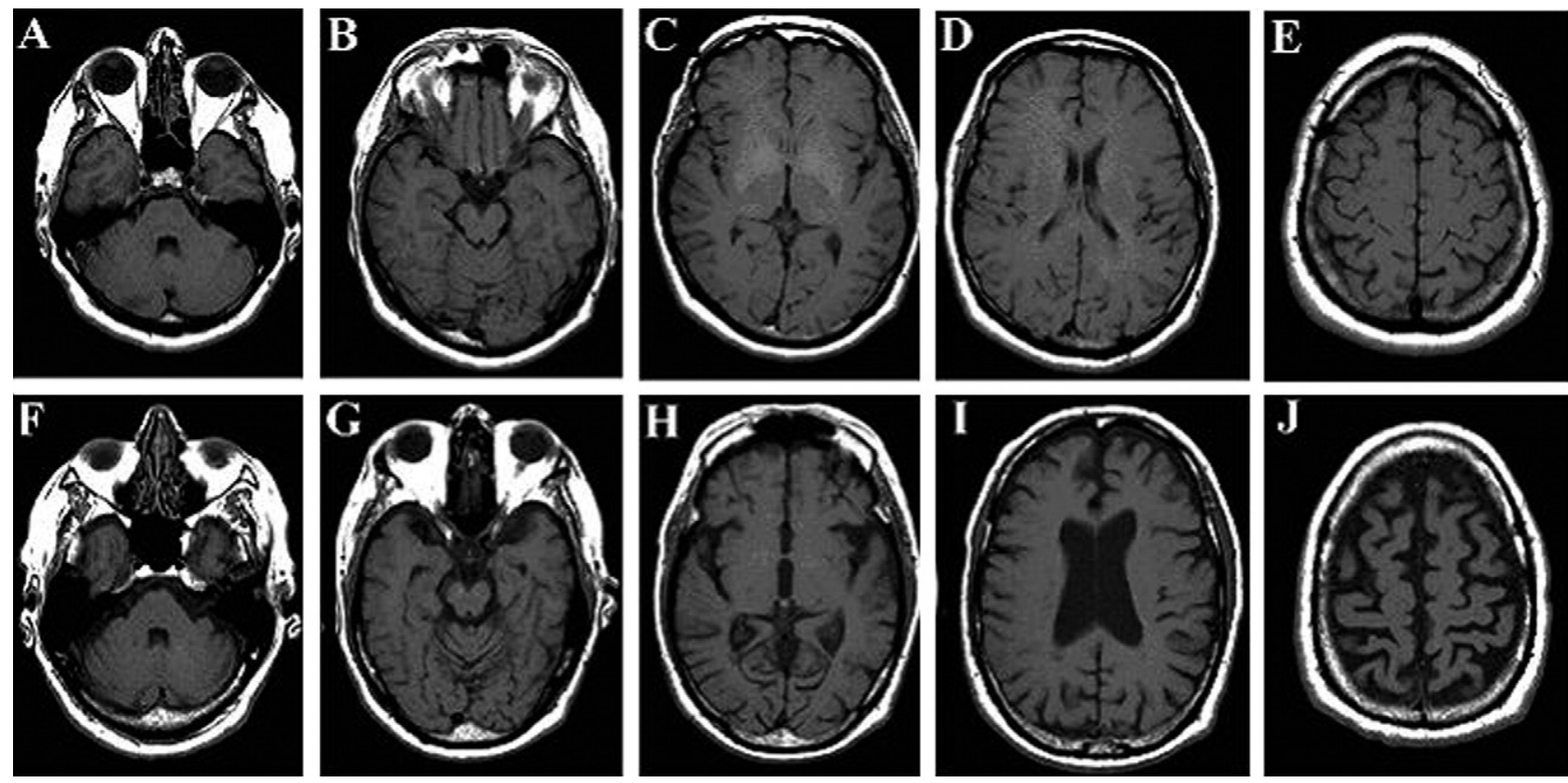

FIG. 6. Widespread brain atrophy in multiple sclerosis (MS). Comparison of noncontrast T1-weighted spin-echo axial MRI scans of a healthy control in the fifth decade (A-E) versus an age-matched patient with secondary-progressive MS (F-J). The patient with MS has moderate physical disability (Expanded Disability Status Scale score of 6) and a disease duration of 12 years. Note widespread supratentorial and infratentorial brain atrophy in the patient with MS (enlargement of the subarachnoid and ventricular CSF spaces including the cortical sulci, Sylvian fissures, basal cisterns, lateral ventricles, and third and lateral ventricles compared to the healthy control).

clinical measures of MS, including physical disability, disease progression, and cognitive function. Although some past studies have shown poor correlations between diffusion measures and clinical disability, ${ }^{127,128}$ with advanced diffusion imaging techniques like DTI, significant correlations have been found in both cross-sectional and longitudinal studies. ${ }^{115,118,122,124,129,130}$ Both GM and WM diffusion changes are related to clinical progression. ${ }^{126}$ Due to its ability to demonstrate longitudinal changes, diffusion imaging could become an outcome measure in drug trials, although this possibility remains unexplored in the published literature. Diffusion imaging is beginning to be applied to the study of the spinal cord in patients with MS (see section "Spinal cord imaging" as follows).

\section{Brain atrophy}

Progressive brain atrophy is being increasingly recognized as a manifestation of the MS disease process (FIGS. 6 and 7). Both qualitative and quantitative (twodimensional and three-dimensional) methods exist for the measurement of brain atrophy. The reader is referred to recent reviews on atrophy in MS that include a discussion of the technical aspects of MRI measurement. ${ }^{131-133}$ The histological basis of CNS atrophy in patients with MS is not well understood. Although primarily reflecting demyelination, axonal loss and neuronal loss, other factors may also affect CNS volume, such as medication effects, fluid status, and inflammation.
Atrophy in patients with MS appears to result in part from previous inflammatory demyelination-related damage in overt lesions. For example, Jasperse et al. ${ }^{134}$ compared conventional MRI measures including T2-lesion volume, T1-hypointense lesion volume, and Gd-enhancing lesions in predictive models of brain atrophy and concluded that T2LV was the best predictor of atrophy. In a longitudinal 14-year analysis, ${ }^{135} \mathrm{~T} 2$-lesion accumulation in the first five years predicted subsequent brain atrophy; however, this accumulation did not account solely for the atrophy seen at 14 years. Another factor potentially contributing to atrophy is brain iron deposition that may cause secondary damage, particularly in GM. ${ }^{136}$

Brain atrophy is typically widespread in patients with MS, including both GM and WM, and both infratentorial and supratentorial areas (FIG 6). With various emerging techniques allowing assessment of regional brain atrophy and segmentation of GM versus WM atrophy, it has become apparent that GM is disproportionately affected compared to WM. ${ }^{137}$ The deep gray nuclei are particularly affected by atrophy, ${ }^{67,138-140}$ and the rate of atrophy in the GM is higher than in the WM in the early stages of MS. ${ }^{141,142}$

Progressive brain atrophy (FIG. 7) has been estimated to occur at a rate of 0.6 to $1.35 \%$ per year, with the highest rate occurring in patients with active RRMS. ${ }^{132}$ However, progressive brain atrophy occurs in all forms of MS, and can be 

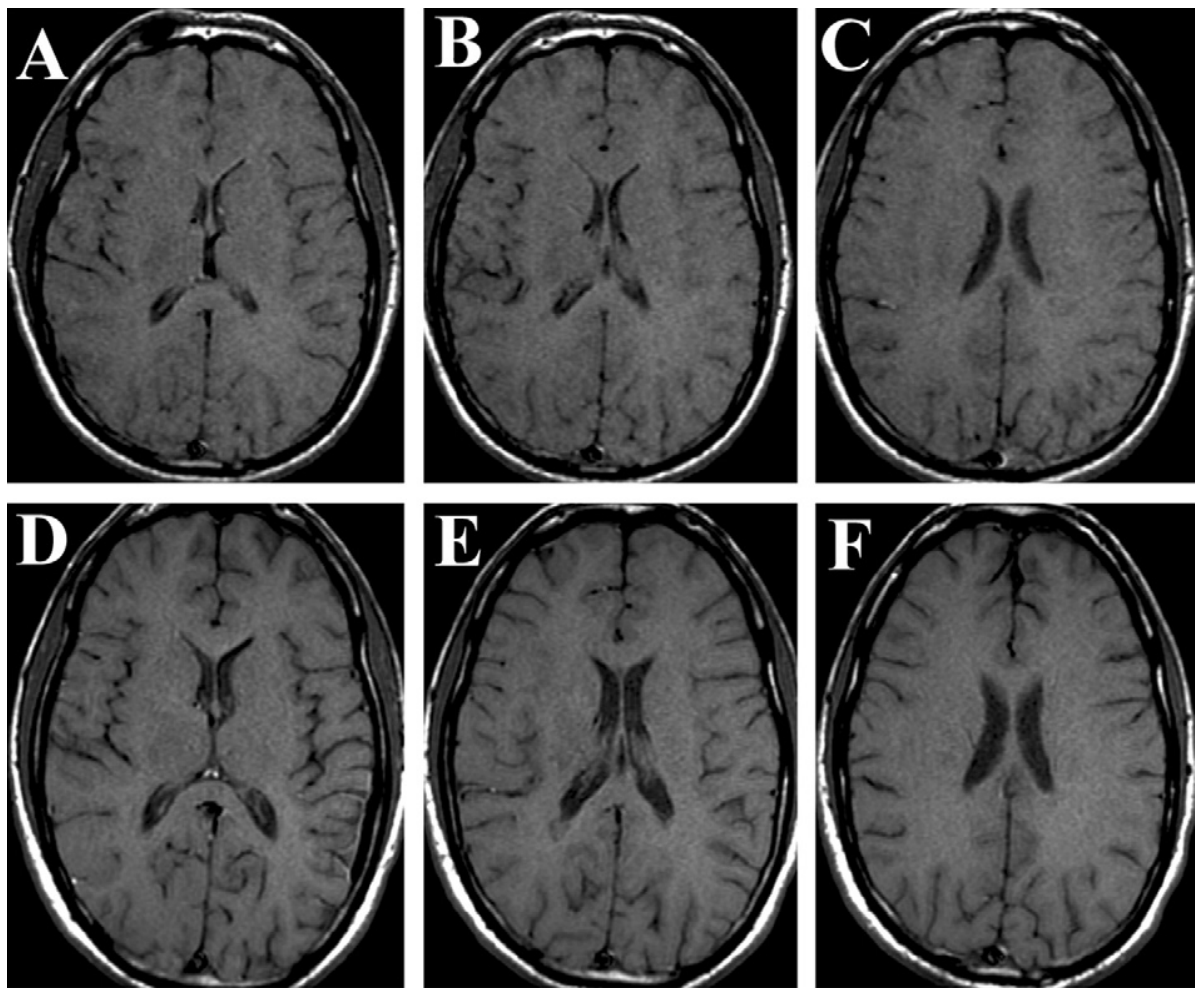

FIG. 7. Progressive brain atrophy in multiple sclerosis (MS). Serial noncontrast T1-weighted spin-echo axial images of 31-year-old man with relapsing-remitting MS showing progressive brain atrophy occurring between 1 year $(A-C)$ and 4 years (D-F) after symptom onset. Note the progressive enlargement of the CSF spaces, including both the subarachnoid spaces (sulci, fissures) and lateral ventricles in comparing the follow-up versus the baseline scan. The brain parenchymal fraction decreased from 0.91 to 0.87 during this time period as determined at the Center for Neurological Imaging. The patient had a neurologic disability on the Expanded Disability Status Scale that increased from 1.0 to 1.5 during this period.

seen early in the course of the disease (in patients with CIS or the initial stages of RRMS). ${ }^{141-143}$ Brain atrophy has been shown to better correlate with clinical status (including both physical disability and cognitive impairment) than with conventional MRI lesion measures. ${ }^{132}$

Several of the disease modifying therapies approved by the FDA (including the interferons, glatiramer acetate, and natalizumab) have shown a benefit on limiting progressive brain atrophy in patients with MS, although results have been somewhat variable and difficult to interpret. ${ }^{132,144}$ Future studies will undoubtedly explore the regional topography of such treatment effects as the relative effect on GM versus WM. ${ }^{145}$ Atrophy measures are being incorporated into studies that explore the efficacy and safety of novel MS therapies. New data have emerged from natalizumab, ${ }^{146}$ autologous hematopoietic stem cell transplantation, ${ }^{147,148}$ and testosterone. ${ }^{149}$ In the phase III placebo-controlled natalizumab trial in patients with RRMS, the patients receiving active therapy had a higher rate of brain volume loss in the first year than patients receiving a placebo, whereas the opposite was seen in the second year. ${ }^{146}$ Similarly, in patients receiving autologous hematopoietic stem cell transplantation, a faster rate of brain volume loss was observed in the first few months than in the pre-treatment period. ${ }^{147}$
However, subsequently, the treatment appears to slow the rate of atrophy. ${ }^{148}$ These results combined with data from previous studies with interferon agents indicate that immunomodulatory agents may reduce brain volume in the first few months by their direct effect on reducing inflammation rather than by accelerating demyelination and axonal loss. One of the clear limitations in using brain atrophy as a longitudinal marker of drug efficacy are the acute effects of medications on brain volume that confound the measurement of true atrophy. ${ }^{150}$

\section{T1- and T2-based measures of diffuse brain injury}

T1 Imaging. T1-relaxation times obtained by T1mapping approaches have been shown to be sensitive, but not specific for underlying pathology in the brain and spinal cord of patients with MS, as recently reviewed. ${ }^{151}$ Such measures can detect diffuse damage in areas of the CNS that are free of overt lesions on conventional MRI scans. ${ }^{94,152-161}$ Furthermore, T1 mapping may be more sensitive than MTR in detecting tissue damage in NAWM. ${ }^{94}$ The most common effect of MS on T1 relaxation is prolongation, which is believed to result from a variety of processes such as edema, demyelination, gliosis, and axonal loss in NAWM $^{94,152-154,156,160}$ and NAGM. ${ }^{152,156,158}$ More 
profound prolongation of $\mathrm{T} 1$ is seen when comparing patients with SPMS to patients with RRMS ${ }^{160}$ and in patients with early RRMS versus normal controls. ${ }^{161}$ T1-mapping data have shown weak to moderate correlations with physical disability. ${ }^{151,154,156}$ Increases in WM relaxation times have been shown to correlate with brain atrophy. ${ }^{152,154}$ Increases in deep GM T1-relaxation times correlate significantly with MS fatigue. ${ }^{158}$ However, one should bear in mind that the disease process may cause $\mathrm{T} 1$ shortening (perhaps related to macrophage activity or metal deposition) $)^{157,162}$ as opposed to T1 prolongation. This offsetting factor might limit the longitudinal sensitivity of T1 mapping measures.

T2 Imaging. As recently reviewed in this journal, ${ }^{163}$ many GM areas (including the thalamus, dentate nucleus, basal ganglia, and rolandic cortex) commonly show hypointensity on $\mathrm{T} 2$-weighted images in patients with MS. Iron deposition has been postulated to be a cause of this hypointensity, as it reduces T2-relaxation times and is found pathologically to be in excess in the MS brain. ${ }^{164}$ Furthermore, biochemical abnormalities related to iron are seen in patients with MS. ${ }^{163}$ It remains unclear whether iron deposition contributes to secondary damage or is purely an epiphenomenon. T2 hypointensity in GM has been related to brain atrophy, physical disability, and cognitive impairment in patients with MS. ${ }^{136,165-168}$ Prior studies determining T2 hypointensity have relied on normalized intensity measurements rather than relaxometric studies. Advanced methods such as $\mathrm{T} 2$ relaxometry and gradient-echo imaging with ultrahigh-field MRI should increase our understanding of the role iron plays in the pathophysiology of MS in the future. ${ }^{151}$ As reviewed recently in this journal, ${ }^{169} \mathrm{~T} 2$ relaxometry techniques have also been useful in evaluating the short component of the T2-relaxation curve in NAWM and overt lesions in patients with MS. The short T2 component is believed to reflect the myelin content. Reduced myelin detected by this technique has been reported in both lesions ${ }^{170-173}$ and NAWM. ${ }^{170}$ An exciting advance in this area was recently reported by $\mathrm{Oh}$ et al., ${ }^{174}$ demonstrating the role of 3 T MRI in detecting decreased myelin content in NAWM in patients with MS.

\section{Spinal cord imaging}

Neuropathologic studies have demonstrated both demyelinating plaques and atrophy of the spinal cord of MS patients. A pathologic study estimated that up to 90\% of MS patients have lesions in their cervical spinal cord. ${ }^{175}$ Approximately $30 \%$ of patients presenting with clinically isolated optic neuritis show evidence of spinal cord disease at the time of presentation. ${ }^{176}$ Demyelination in the cord affects both GM and WM. ${ }^{177}$ Conventional MRI has revealed that patients with RRMS tend to have focal T2 hyperintensity while patients with PPMS and SPMS additionally are likely to have confluent lesions. Gd enhancement is seen less frequently in the spinal cord than in the brain, and T1 hypointensity in the spinal cord is rare. Lesions in the spinal cord are often associated with clinical symptoms.

Conventional MRI of the spinal cord in MS has lagged behind that of brain MRI due to technical limitations of spinal cord imaging. ${ }^{178}$ The correlations in cross-sectional and longitudinal studies of spinal cord lesions with clinical involvement have been moderate at best. ${ }^{179} \mathrm{Cord}$ atrophy, on the other hand, has shown better correlation with disability. ${ }^{180}$ Recently, Carbonell-Caballero et al. ${ }^{181}$ showed that an automated method of calculating cervical cord volume was highly accurate and sensitive to spinal cord atrophy in patients with MS. Automation has the benefits of improving reliability and significantly reducing processing time, and should generate additional interest in the near future.

Advanced MRI techniques are of growing interest to add more specificity and sensitivity to the non-invasive evaluation of spinal cord disease in patients with MS. These include MTI, diffusion imaging, and MRS. DTI of the spinal cord has been recently reviewed both from a clinical and technical standpoint in this journal. ${ }^{182}$ DTI performed in the cervical cord of patients with MS typically shows decreased FA and increased mean diffusivity compared to controls and correlates significantly with disability. ${ }^{183-185}$ MRS is just beginning to be applied to the study of the spinal cord in MS. When compared to healthy controls, reduced NAA was seen in the NAWM of the cervical cord of MS patients. ${ }^{186}$ Recently, a protocol enabling MRS for use in spinal imaging has been developed on a $3 \mathrm{~T}$ platform. ${ }^{187}$ Average MTR in the spinal cord of patients with RRMS or CIS does not differ significantly from normal controls. ${ }^{188}$ MTR also did not differ between patients with PPMS versus SPMS, ${ }^{189}$ although patients with PPMS showed lower MTR than patients with RRMS. ${ }^{188}$

\section{Ultrahigh-field strength MRI}

The availability of ultrahigh-field strength scanners (i.e., $3 \mathrm{~T}$ and higher) has the potential to revolutionize research and clinical care in MS. Such scanners reveal MS lesions in the brain with more sensitivity than $1.5 \mathrm{~T}$ scanners (FIG. 8). ${ }^{190-195}$ Keiper et al. ${ }^{190}$ found that observers were able to consensually detect more lesions at $4 \mathrm{~T}$ than $1.5 \mathrm{~T}$, including the ability to distinguish perivascular lesions from normal perivascular spaces. Furthermore, cerebral lesion volume tends to increase as magnet strength increases. ${ }^{190}$ In a study involving 25 patients with MS, Sicotte et al. ${ }^{192}$ showed an increased number and volume of Gd-enhancing lesions and increased volume of T-2 hyperintense lesions at $3 \mathrm{~T}$ versus $1.5 \mathrm{~T}$. Wattjes et al. ${ }^{193}$ scanned 40 patients with CIS at $1.5 \mathrm{~T}$ and $3 \mathrm{~T}$ and determined that 11 additional 

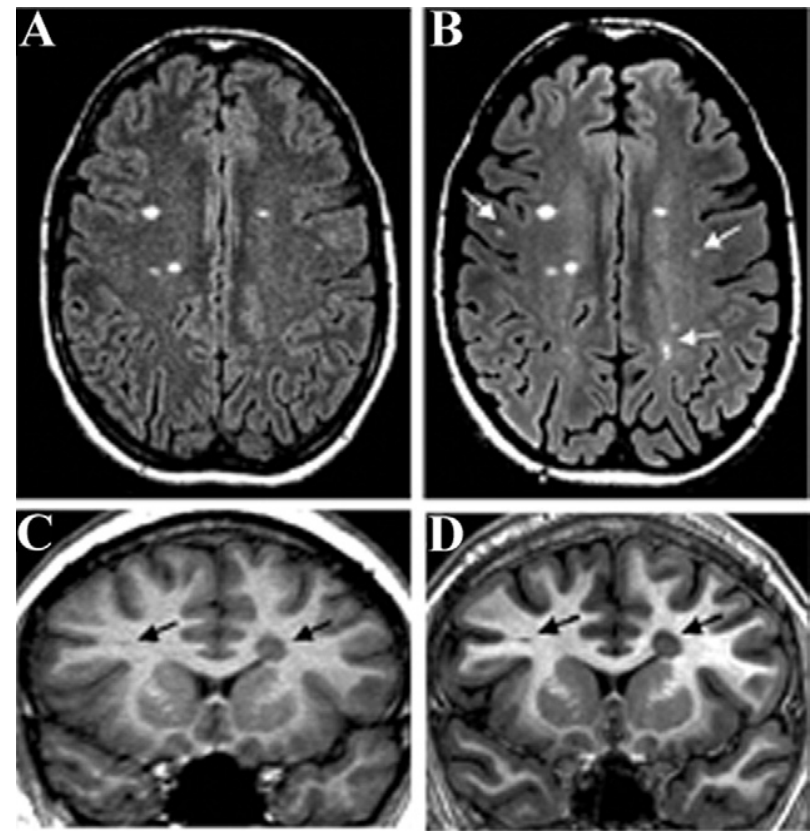

FIG. 8. A comparison of 1.5 Tesla $(T)$ and $3 T$ MRI is shown in a 48-year-old woman with secondary progressive MS (A, B) and a 21 year-old man with relapsing-remitting MS (C, D). The 1.5 T axial fluid-attenuated inversion-recovery images (A) and coronal spoiled gradient recall images $(C)$ of the brain and $3 T$ images ( $B$, D) of the same regions with equivalent pulse sequences on each patient display the improved sensitivity in lesion-detecting capabilities (arrows) and tissue resolution (tissue CSF and graywhite matter distinction) of the $3 \mathrm{~T}$ scanner.

patients fulfilled MS diagnostic criteria at the higher, rather than lower, field strength.

Ultrahigh-field imaging has particular relevance in the detection of cortical lesions in patients with MS. Wattjes et al. ${ }^{13}$ studied nine patients with MS using DIR, FLAIR, and T2-weighted sequences at $3 \mathrm{~T}$ and found that DIR was more sensitive in detecting lesions than FLAIR or $\mathrm{T} 2$ especially in the infratentorial region. Both DIR and FLAIR showed higher lesion counts in detecting juxtacortical, mixed WM and GM, and periventricular lesions when compared to conventional T2 sequences. In an MRI histologic correlation study, Kangarlu et al. ${ }^{191}$ recently found that $8 \mathrm{~T}$ revealed many plaques that were undetected at $1.5 \mathrm{~T}$, particularly those in the cerebral cortex.

Ultrahigh-field MRI also has applications to improving MRS,${ }^{61}$ MTI,${ }^{196}$ DTI, ${ }^{111}$ and relaxometry studies ${ }^{151,174}$ in MS. However, several challenges remain in using ultrahigh-field MRI. Acquisition protocols are still being developed and optimized. Patient safety issues and artifacts are being understood and addressed. ${ }^{195,197}$

\section{CONCLUSIONS}

We have reviewed the current understanding of conventional and advanced MRI techniques used in the study of patients with MS. We have seen that the role of conventional MRI measures has far exceeded its primary objective of diagnosis and management of MS. However, these conventional measures show only moderate correlations with neurological impairment and disease progression, and remain generally nonspecific for the underlying pathology. Advanced MRI techniques hold promise in uncoupling the MRI clinical paradox and may contribute to a more sensitive and specific depiction of clinically relevant underlying pathology. These advanced techniques continue to define the future of MS research using MRI. We conclude that MRI has witnessed unprecedented growth and development during the past several years and continues to provide an expanding toolbox to uncover the complexities of this intriguing disease.

Acknowledgments: This work was supported by research grants to Dr. Bakshi from the National Institutes of Health (NIH-NINDS 1 K23 NS42379-01) and National Multiple Sclerosis Society (RG3705A1; RG3798A2). We thank Ms. Sophie Tamm for her editorial assistance.

\section{REFERENCES}

1. Bakshi R, Minagar A, Jaisani Z, Wolinsky JS. Imaging of multiple sclerosis: role in neurotherapeutics. NeuroRx 2005;2:277303.

2. Filippi M, Rocca MA. Conventional MRI in multiple sclerosis. J Neuroimaging 2007;17:3S-9S.

3. Zivadinov R, Leist TP. Clinical-magnetic resonance imaging correlations in multiple sclerosis. J Neuroimaging 2005;15:10S-21S.

4. Hickman SJ. Optic nerve imaging in multiple sclerosis. J Neuroimaging 2007;17:42S-45S.

5. Cagnin A, Kassiou M, Meikle SR, Banati RB. Positron emission tomography imaging of neuroinflammation. Neurotherapeutics 2007;4:443-452.

6. Buckle GJ. Functional magnetic resonance imaging and multiple sclerosis: the evidence for neuronal plasticity. J Neuroimaging 2005; 15:82S-93S.

7. Meier DS, Weiner HL, Guttmann CR. Time-series modeling of multiple sclerosis disease activity: a promising window on disease progression and repair potential? Neurotherapeutics 2007;4: 485-498.

8. Patola WB, Coulter BA, Chipperfield PM, Lingawi SS. A comparison of conventional spin-echo and fast spin-echo in the detection of multiple sclerosis. J Magn Reson Imaging 2001;13: 657-667.

9. Bakshi R, Ariyaratana S, Benedict RH, Jacobs L. Fluid-attenuated inversion recovery magnetic resonance imaging detects cortical and juxtacortical multiple sclerosis lesions. Arch Neurol 2001; 58:742-748.

10. Geurts JJ, Pouwels PJ, Uitdehaag BM, Polman CH, Barkhof F, Castelijns JA. Intracortical lesions in multiple sclerosis: improved detection with 3D double inversion-recovery MR imaging. Radiology 2005;236:254-260.

11. Pirko I, Lucchinetti CF, Sriram S, Bakshi R. Gray matter involvement in multiple sclerosis. Neurology 2007;68:634-642.

12. Wattjes MP, Lutterbey GG, Harzheim M, et al. Imaging of inflammatory lesions at 3.0 Tesla in patients with clinically isolated syndromes suggestive of multiple sclerosis: a comparison of fluid-attenuated inversion recovery with $\mathrm{T} 2$ turbo spin-echo. Eur Radiol 2006;16:1494-1500.

13. Wattjes MP, Lutterbey GG, Gieseke J, et al. Double inversion recovery brain imaging at 3T: diagnostic value in the detection of multiple sclerosis lesions. AJNR Am J Neuroradiol 2007;28:5459. 
14. Fillippi M, Yousri T, Baratti C, et al. Quantitative brain MRI lesion load predicts the course of clinically isolated syndromes suggestive of multiple sclerosis. Neurology 1994;44:635-641.

15. Barkhof F, Filippi M, Miller DH, et al. Comparison of MRI criteria at first presentation to predict conversion to clinically definite multiple sclerosis. Brain 1997;120:2059-2069.

16. O'Riordan JI, Thompson AJ, Kingsley DP, et al. The prognostic value of brain MRI in clinically isolated syndromes of the CNS. A 10-year follow-up. Brain 1998;121:495-503.

17. Brex PA, Ciccarelli O, O'Riordan JI, Sailer M, Thompson AJ, Miller DH. A longitudinal study of abnormalities on MRI and disability from multiple sclerosis. N Engl J Med 2002;346:158 164.

18. Gauthier SA, Mandel M, Guttmann CR, et al. Predicting shortterm disability in multiple sclerosis. Neurology 2007;68:20592065.

19. Rudick RA, Lee JC, Simon J, Fisher E. Significance of T2 lesions in multiple sclerosis: a 13-year longitudinal study. Ann Neurol 2006;60:236-242.

20. Li DK, Held U, Petkau J, et al. MRI T2 lesion burden in multiple sclerosis: a plateauing relationship with clinical disability. Neurology 2006;66:1384-1389.

21. Bitsch A, Kuhlmann T, Stadelmann C, Lassmann H, Lucchinetti C, Brueck W. A longitudinal MRI study of histopathologically defined hypointense multiple sclerosis lesions. Ann Neurol 2001; 49:793-796.

22. Fisher E, Chang A, Fox RJ, et al. Imaging correlates of axonal swelling in chronic multiple sclerosis brains. Ann Neurol 2007 Apr 11; [Epub ahead of print].

23. Paolillo A, Pozzilli C, Gasperini C, et al. Brain atrophy in relapsing-remitting multiple sclerosis: relationship with 'black holes', disease duration and clinical disability. J Neurol Sci 2000;174: $85-91$.

24. Sailer M, Losseff NA, Wang L, et al. T1 lesion load and cerebral atrophy as a marker for clinical progression in patients with multiple sclerosis: a prospective 18 months follow-up study. Eur J Neurol 2001;8:37-42.

25. Adams H-P, Wagner S, Sobel SF, et al. Hypointense and hyperintense lesions on magnetic resonance imaging in secondaryprogressive MS patients. Eur Neurol 1999;42:52-63.

26. Molyneux PD, Brex PA, Fogg C, et al. The precision of T1 hypointense lesion volume quantification in multiple sclerosis treatment trials: a multicenter study. Mult Scler 2000;6:237-240.

27. Datta S, Sajja BR, He R, Wolinsky JS, Gupta RK, Narayana PA. Segmentation and quantification of black holes in multiple sclerosis. Neuroimage 2006;29:467-474.

28. Truyen L, van Waesberghe JH, van Walderveen MA, et al. Accumulation of hypointense lesions ("black holes") on T1 spinecho MRI correlates with disease progression in multiple sclerosis. Neurology 1996;47:1469-1476.

29. van Walderveen MA, Lycklama A, Nijeholt GJ, et al. Hypointense lesions on T1-weighted spin-echo magnetic resonance imaging: relation to clinical characteristics in subgroups of patients with multiple sclerosis. Arch Neurol 2001;58:76-81.

30. Bagnato F, Jeffries N, Richert ND, et al. Evolution of T1 black holes in patients with multiple sclerosis imaged monthly for 4 years. Brain 2003;126:1782-1789.

31. van Waesberghe JH, van Walderveen MA, Castelijns JA, et al. Patterns of lesion development in multiple sclerosis: longitudinal observations with $\mathrm{T} 1$-weighted spin-echo and magnetization transfer MR. AJNR Am J Neuroradiol 1998;19:675-683.

32. Bruck W, Bitsch A, Kolenda H, et al. Inflammatory central nervous system demyelination: correlation of magnetic resonance imaging findings with lesion pathology. Ann Neurol 1997;42: 783-793.

33. Silver NC, Good CD, Barker GJ, et al. Sensitivity of contrast enhanced MRI in multiple sclerosis. Effects of gadolinium dose, magnetization transfer contrast and delayed imaging. Brain 1997; 120:1149-1161

34. Simon JH, Li D, Traboulsee A, Coyle PK, et al. Standardized MR imaging protocol for multiple sclerosis: consortium of MS Centers consensus guidelines. AJNR Am J Neuroradiol 2006;27:455461.
35. Wolansky LJ, Haghighi MH, Sevdalis E, et al. Safety of serial monthly administration of triple-dose gadopentetate dimeglumine in multiple sclerosis patients: preliminary results of the BECOME trial. J Neuroimaging 2005;15:289-290.

36. Datta S, Sajja BR, He R, Gupta RK, Wolinsky JS, Narayana PA. Segmentation of gadolinium-enhanced lesions on MRI in multiple sclerosis. J Magn Reson Imaging 2007;25:932-937.

37. Cotton F, Weiner HL, Jolesz FA, Guttmann CR. MRI contrast uptake in new lesions in relapsing-remitting MS followed at weekly intervals. Neurology 2003;60;640-646.

38. Masdeu JC, Moreira J, Trasi S, Visintainer P, Cavaliere R, Grundman $M$. The open ring: a new imaging sign in demyelinating disease. J Neuroimaging 1996;6:104-107.

39. Rovira A, Alonso J, Cucurella G, et al. Evolution of multiple sclerosis lesions on serial contrast-enhanced T1- weighted and magnetization-transfer MR images. AJNR Am J Neuroradiol 1999;20:1939-1945.

40. Roychowdhury S, Maldjian JA, Grossman RI. Multiple sclerosis: comparison of trace apparent diffusion coefficients with MR enhancement pattern of lesions. AJNR Am J Neuroradiol 2000;21: $869-874$

41. Minneboo A, Uitdehaag BM, Ader HJ, Barkhof F, Polman CH, Castelijns JA. Patterns of enhancing lesion evolution in multiple sclerosis are uniform within patients. Neurology 2005;65:56-61.

42. Leist TP, Gobbini MI, Frank JA, McFarland HF. Enhancing magnetic resonance imaging lesions and cerebral atrophy in patients with relapsing multiple sclerosis. Arch Neurol 2001;58:5760.

43. Silver NC, Tofts PS, Symms MR, et al. Quantitative contrastenhanced magnetic resonance imaging to evaluate blood-brain barrier integrity in multiple sclerosis: a preliminary study. Mult Scler 2001;7:75-82.

44. Soon D, Tozer DJ, Altmann DR, Tofts PS, Miller DH. Quantification of subtle blood-brain barrier disruption in non-enhancing lesions in multiple sclerosis: a study of disease and lesion subtypes. Mult Scler 2007 Apr 27; [Epub ahead of print].

45. McFarland HF, Stone LA, Calabresi PA, Maloni H, Bash CN, Frank JA. MRI studies of multiple sclerosis: implications for the natural history of the disease and for monitoring effectiveness of experimental therapies. Mult Scler 1996;2:198-205.

46. Rashid W, Davies GR, Chard DT, et al. Relationship of triple dose contrast enhanced lesions with clinical measures and brain atrophy in early relapsing-remitting multiple sclerosis: a two-year longitudinal study. Mult Scler 2007;13:178-185.

47. Kappos L, Moeri D, Radue EW, et al. Predictive value of gadolinium-enhanced magnetic resonance imaging for relapse rate and changes in disability or impairment in multiple sclerosis: a metaanalysis. Lancet 1999;353:964-969.

48. Molyneux PD, Filippi M, Barkhof F, et al. Correlations between monthly enhanced MRI lesion rate and changes in T2 lesion volume in multiple sclerosis. Ann Neurol 1998;43:332-339.

49. Smith ME, Stone LA, Albert PS, et al. Clinical worsening in multiple sclerosis is associated with increased frequency and area of gadopentetate dimenglumine-enhancing magnetic resonance imaging lesions. Ann Neurol 1993;33:480-489.

50. Deloire MS, Touil T, Brochet B, Dousset V, Caille JM, Petry KG. Macrophage brain infiltration in experimental autoimmune encephalomyelitis is not completely compromised by suppressed T-cell invasion: in vivo magnetic resonance imaging illustration in effective anti-VLA-4 antibody treatment. Mult Scler 2004;10: $540-548$

51. Petry KG, Boiziau C, Dousset V, Brochet B. Magnetic resonance imaging of human brain macrophage infiltration. Neurotherapeutics 2007;4:434-442.

52. Dousset V, Brochet B, Deloire MS, et al. MR imaging of relapsing multiple sclerosis patients using ultra-small-particle iron oxide and compared with gadolinium. AJNR Am J Neuroradiol 2006;27:1000-1005.

53. McDonald WI, Compston A, Edan G, et al. Recommended diagnostic criteria for multiple sclerosis: guidelines from the International Panel on the diagnosis of multiple sclerosis. Ann Neurol 2001;50:121-127.

54. Polman CH, Reingold SC, Edan G, et al. Diagnostic criteria for 
multiple sclerosis: 2005 revisions to the "McDonald Criteria." Ann Neurol 2005;58:840-846.

55. Lin A, Ross BD, Harris K, et al. Efficacy of proton magnetic resonance spectroscopy in neurological diagnosis and neurotherapeutic decision making. NeuroRx 2005;2:197-214.

56. Rosen Y, Lenkinski RE. Recent advances in magnetic resonance neurospectroscopy. Neurotherapeutics 2007;4:330-345.

57. Narayana PA. Magnetic resonance spectroscopy in the monitoring of multiple sclerosis. J Neuroimaging 2005;15:46S-57S.

58. De Stefano N, Filippi M. MR spectroscopy in multiple sclerosis. J Neuroimaging 2007;17:31S-35S.

59. Davie CA, Hawkins CP, Barker GJ, et al. Serial proton magnetic resonance spectroscopy in acute multiple sclerosis lesions. Brain 1994;117:49-58.

60. Husted CA, Goodin DS, Hugg JW, et al. Biochemical alterations in multiple sclerosis lesions and normal-appearing white matter detected by in vivo $31 \mathrm{P}$ and $1 \mathrm{H}$ spectroscopic imaging. Ann Neurol 1994:36:157-165.

61. Srinivasan R, Sailasuta N, Hurd R, et al. Evidence of elevated glutamate in multiple sclerosis using magnetic resonance spectroscopy at $3 \mathrm{~T}$. Brain 2005;128:1016-1025.

62. De Stefano N, Matthews PM, Antel JP, et al. Chemical pathology of acute demyelinating lesions and its correlation with disability. Ann Neurol 1995;38:901-909.

63. Narayana PA, Doyle TJ, Lai D, et al. Serial proton magnetic resonance spectroscopic imaging, contrast-enhanced magnetic resonance imaging, and quantitative lesion volumetry in multiple sclerosis. Ann Neurol 1998;43:56-71.

64. Narayanan S, Fu L, Pioro E, De Stefano N, et al. Imaging of axonal damage in multiple sclerosis: spatial distribution of magnetic resonance imaging lesions. Ann Neurol 1997;41:385-391.

65. Gonen O, Oberndorfer TA, Inglese M, Babb JS, Herbert J, Grossman RI. Reproducibility of three whole-brain N-acetylaspartate decline cohorts in relapsing-remitting multiple sclerosis. AJNR Am J Neuroradiol 2007;28:267-271.

66. Fernando KT, McLean MA, Chard DT, et al. Elevated white matter myo-inositol in clinically isolated syndromes suggestive of multiple sclerosis. Brain 2004;127:1361-1369.

67. Wylezinska M, Cifelli A, Jezzard P, Palace J, Alecci M, Matthews PM. Thalamic neurodegeneration in relapsing-remitting multiple sclerosis. Neurology 2003;60:1949-1954.

68. Sharma R, Narayana PA, Wolinsky JS. Grey matter abnormalities in multiple sclerosis: proton magnetic resonance spectroscopic imaging. Mult Scler 2001;7:221-226.

69. Chard DT, Griffin CM, McLean MA, et al. Brain metabolite changes in cortical grey and normal-appearing white matter in clinically early relapsing-remitting multiple sclerosis. Brain 2002; 125:2342-2352.

70. Sastre-Garriga J, Ingle GT, Chard DT, et al. Metabolite changes in normal-appearing gray and white matter are linked with disability in early primary progressive multiple sclerosis. Arch Neurol 2005;62:569-573.

71. De Stefano N, Matthews PM, Fu L, et al. Axonal damage correlates with disability in patients with relapsing-remitting multiple sclerosis. Results of a longitudinal magnetic resonance spectroscopy study. Brain 1998;121:1469-1477.

72. De Stefano N, Narayanan S, Francis GS, et al. Evidence of axonal damage in the early stages of multiple sclerosis and its relevance to disability. Arch Neurol 2001;58:65-70.

73. Bonneville F, Moriarty DM, Li BS, Babb JS, Grossman RI, Gonen O. Whole-brain N-acetylaspartate concentration: correlation with T2-weighted lesion volume and expanded disability status scale score in cases of relapsing-remitting multiple sclerosis. AJNR Am J Neuroradiol 2002;233:371-375.

74. Pan JW, Krupp LB, Elkins LE, Coyle PK. Cognitive dysfunction lateralizes with NAA in multiple sclerosis. Appl Neuropsychol 2001;8:155-160.

75. Ruiz-Pena JL, Pinero P, Sellers G, et al. Magnetic resonance spectroscopy of normal appearing white matter in early relapsingremitting multiple sclerosis: correlations between disability and spectroscopy. BMC Neurol 2004;4:8.

76. Gadea M, Martinez-Bisbal MC, Marti-Bonmati L, et al. Spectroscopic axonal damage of the right locus coeruleus relates to selective attention impairment in early stage relapsing-remitting multiple sclerosis. Brain 2004;127:89-98.

77. Mathiesen HK, Jonsson A, Tscherning T, et al. Correlation of global $\mathrm{N}$-acetyl aspartate with cognitive impairment in multiple sclerosis. Arch Neurol 2006;63:533-536.

78. Christodoulou C, Krupp LB, Liang Z, et al. Cognitive performance and MR markers of cerebral injury in cognitively impaired MS patients. Neurology 2003;60:1793-1798.

79. Horsfield MA. Magnetization transfer imaging in multiple sclerosis. J Neuroimaging 2005;15(4 Suppl):58S-67S.

80. Filippi M, Rocca MA. Magnetization transfer magnetic resonance imaging of the brain, spinal cord, and optic nerve. Neurotherapeutics 2007;4:401-413.

81. Hiehle JF Jr, Grossman RI, Ramer KN, Gonzalez-Scarano F, Cohen JA. Magnetization transfer effects in MR-detected multiple sclerosis lesions: comparison with gadolinium enhanced spinecho images and nonenhanced T1-weighted images. AJNR Am J Neuroradiol 1995;16:69-77.

82. Karampekios S, Papanikolaou N, Papadaki E, et al. Quantification of magnetization transfer rate and native T1 relaxation time of the brain: correlation with magnetization transfer ratio measurements in patients with multiple sclerosis. Neuroradiology 2005;47:189 196.

83. Rocca MA, Mastronardo G, Rodegher M, et al. Long-term changes of magnetization transfer-derived measures from patients with relapsing-remitting and secondary progressive multiple sclerosis. AJNR Am J Neuroradiol 1999;20:821-827.

84. Iannucci G, Tortorella C, Rovaris M, et al. Prognostic value of MR and magnetization transfer imaging findings in patients with clinically isolated syndromes suggestive of multiple sclerosis at presentation. AJNR Am J Neuroradiol 2000;21:1034-1038.

85. De Stefano N, Battaglini M, Stromillo ML, et al. Brain damage as detected by magnetization transfer imaging is less pronounced in benign than in early relapsing multiple sclerosis. Brain 2006;129: $2008-2016$

86. Pike GB, De Stefano N, Narayanan S, et al. Multiple sclerosis: magnetization transfer MR imaging of white matter before lesion appearance on T2-weighted images. Radiology 2000;215:824830.

87. Silver NC, Lai M, Symms MR, Barker GJ, et al. Serial magnetization transfer imaging to characterize the early evolution of new MS lesions. Neurology 1998;51:758-764.

88. Filippi M, Rocca MA, Martino G, Horsfield MA, Comi G. Magnetization transfer changes in the normal appearing white matter precede the appearance of enhancing lesions in patients with multiple sclerosis. Ann Neurol 1998;43:809-814.

89. van Waesberghe JH, Kamphorst W, De Groot CJ, et al. Axonal loss in multiple sclerosis lesions: magnetic resonance imaging insights into substrates of disability. Ann Neurol 1999;46:747754.

90. Chen JT, Kuhlmann T, Jansen GH, et al. Voxel-based analysis of the evolution of magnetization transfer ratio to quantify remyelination and demyelination with histopathological validation in a multiple sclerosis lesion. Neuroimage 2007;36:1152-1158.

91. Filippi M, Campi A, Dousset V, et al. A magnetization transfer imaging study of normal-appearing white matter in multiple sclerosis. Neurology 1995;45:478-482.

92. Loevner LA, Grossman RI, Cohen JA, Lexa FJ, Kessler D, Kolson DL. Microscopic disease in normal-appearing white matter on conventional MR imaging in patients with multiple sclerosis: assessment with magnetization-transfer measurements. Radiology 1995;196:511-515.

93. Ramio-Torrenta L, Sastre-Garriga J, Ingle GT, et al. Abnormalities in normal appearing tissues in early primary progressive multiple sclerosis and their relation to disability: a tissue specific magnetisation transfer study. J Neurol Neurosurg Psychiatry 2006;77:40-45.

94. Vrenken H, Geurts JJ, Knol DL, et al. Normal-appearing white matter changes vary with distance to lesions in multiple sclerosis. AJNR Am J Neuroradiol 2006;27:2005-2011.

95. Richert ND, Ostuni JL, Bash CN, Duyn JH, McFarland HF, Frank JA. Serial whole-brain magnetization transfer imaging in patients with relapsing-remitting multiple sclerosis at baseline and during 
treatment with interferon beta-1b. AJNR Am J Neuroradiol 1998;19:1705-1713.

96. Ge Y, Grossman RI, Udupa JK, et al. Magnetization transfer ratio histogram analysis of gray matter in relapsing-remitting multiple sclerosis. AJNR Am J Neuroradiol 2001;22:470-475.

97. Audoin B, Davies G, Rashid W, Fisniku L, Thompson AJ, Miller DH. Voxel-based analysis of grey matter magnetization transfer ratio maps in early relapsing remitting multiple sclerosis. Mult Scler 2007;13:483-489.

98. Fernando KT, Tozer DJ, Miszkiel KA, et al. Magnetization transfer histograms in clinically isolated syndromes suggestive of multiple sclerosis. Brain 2005;128:2911-2925.

99. Davies GR, Ramio-Torrenta L, Hadjiprocopis A, et al. Evidence for gray matter MTR abnormality in minimally disabled patients with early relapsing-remitting multiple sclerosis. J Neurol Neurosurg Psychiatry 2004;75:998-1002.

100. Sharma J, Zivadinov R, Jaisani Z, et al. A magnetization transfer MRI study of deep gray matter involvement in multiple sclerosis. J Neuroimaging 2006;16:302-310.

101. Oreja-Guevara C, Charil A, Caputo D, Cavarretta R, Sormani MP, Filippi M. Magnetization transfer magnetic resonance imaging and clinical changes in patients with relapsing-remitting multiple sclerosis. Arch Neurol 2006;63:736-740.

102. Iannucci G, Minicucci L, Rodegher M, et al. Correlations between clinical and MRI involvement in multiple sclerosis: assessment using T(1), T(2) and MT histograms. J Neurol Sci 1999; 171:121-129.

103. Davies GR, Altmann DR, Rashid W, et al. Emergence of thalamic magnetization transfer ratio abnormality in early relapsing-remitting multiple sclerosis. Mult Scler 2005;11:276-281.

104. Khaleeli Z, Sastre-Garriga J, Ciccarelli O, Miller DH, Thompson AJ. Magnetisation transfer ratio in the normal appearing white matter predicts progression of disability over one year in early primary progressive MS. J Neurol Neurosurg Psychiatry 2007 Feb 7;[Epub ahead of print].

105. van Buchem MA, Grossman RI, Armstrong C, et al. Correlation of volumetric magnetization transfer imaging with clinical data in MS. Neurology 1998;50:1609-1617.

106. Filippi M, Tortorella C, Rovaris M, et al. Changes in the normal appearing brain tissue and cognitive impairment in multiple sclerosis. J Neurol Neurosurg Psychiatry 2000;68:157-161.

107. Cox D, Pelletier D, Genain C, et al. The unique impact of changes in normal appearing brain tissue on cognitive dysfunction in secondary progressive multiple sclerosis patients. Mult Scler 2004;10:626-629.

108. Ranjeva JP, Audoin B, Au Duong MV, et al. Local tissue damage assessed with statistical mapping analysis of brain magnetization transfer ratio: relationship with functional status of patients in the earliest stage of multiple sclerosis. AJNR Am J Neuroradiol 2005;26:119-127.

109. Agosta F, Rovaris M, Pagani E, Sormani MP, Comi G, Filippi M. Magnetization transfer MRI metrics predict the accumulation of disability 8 years later in patients with multiple sclerosis. Brain 2006;129:2620-2627.

110. Alexander AL, Lee JE, Lazar M, Field AS. Diffusion tensor imaging of the brain. Neurotherapeutics 2007;4:316-329.

111. Goldberg-Zimring D, Mewes AU, Maddah M, Warfield SK. Diffusion tensor magnetic resonance imaging in multiple sclerosis. J Neuroimaging 2005; 15:68-81.

112. Horsfield MA, Lai M, Webb SL, et al. Apparent diffusion coefficients in benign and secondary progressive multiple sclerosis by nuclear magnetic resonance. Magn Reson Med 1996;36:393400.

113. Bammer R, Augustin M, Strasser-Fuchs S, et al. Magnetic resonance diffusion tensor imaging for characterizing diffuse and focal white matter abnormalities in multiple sclerosis. Magn Reson Med 2000;44:583-591.

114. Werring DJ, Brassat D, Droogan AG, et al. The pathogenesis of lesions and normal-appearing white matter changes in multiple sclerosis: a serial diffusion MRI study. Brain 2000;123:16671676.
115. Filippi M, Cercignani M, Inglese M, Horsfield MA, Comi G. Diffusion tensor magnetic resonance imaging in multiple sclerosis. Neurology 2001;56:304-11.

116. Schmierer K, Wheeler-Kingshott CA, Boulby PA, et al. Diffusion tensor imaging of post mortem multiple sclerosis brain. Neuroimage 2007;35:467-477.

117. Henry RG, Oh J, Nelson SJ, Pelletier D. Directional diffusion in relapsing-remitting multiple sclerosis: a possible in vivo signature of Wallerian degeneration. J Magn Reson Imaging 2003;8:420 426.

118. Ciccarelli O, Werring DJ, Wheeler-Kingshott CA, et al. Investigation of MS normal-appearing brain using diffusion tensor MRI with clinical correlations. Neurology 2001;56:926-933.

119. Ceccarelli A, Rocca MA, Falini A, et al. Normal-appearing white and grey matter damage in MS: A volumetric and diffusion tensor MRI study at 3.0 Tesla. J Neurol 2007;254:513-518.

120. Coombs BD, Best A, Brown MS, et al. Multiple sclerosis pathology in the normal and abnormal appearing white matter of the corpus callosum by diffusion tensor imaging. Mult Scler 2004; 10:392-397.

121. Cader S, Johansen-Berg H, Wylezinska M, et al. Discordant white matter $\mathrm{N}$-acetylasparate and diffusion MRI measures suggest that chronic metabolic dysfunction contributes to axonal pathology in multiple sclerosis. Neuroimage 2007;36:19-27.

122. Audoin B, Guye M, Reuter F, et al. Structure of WM bundles constituting the working memory system in early multiple sclerosis: a quantitative DTI tractography study. Neuroimage 2007; 36:1324-1330.

123. Saindane AM, Law M, Ge Y, et al. Correlation of diffusion tensor and dynamic perfusion MR imaging metrics in normal-appearing corpus callosum: support for primary hypoperfusion in multiple sclerosis. AJNR Am J Neuroradiol 2007:28;767-772.

124. Wilson M, Tench CR, Morgan PS, Blumhardt LD. Pyramidal tract mapping by diffusion tensor magnetic resonance imaging in multiple sclerosis: improving correlations with disability. J Neurol Neurosurg Psychiatry 2003;74:203-207.

125. Fabiano AJ, Sharma J, Weinstock-Guttman B, Benedict RH, Zivadinov $\mathrm{R}$, Bakshi $\mathrm{R}$. Thalamic involvement in multiple sclerosis: a diffusion-weighted magnetic resonance imaging study. J Neuroimaging 2003;13:307-314

126. Rovaris M, Gallo A, Valsasina P, et al. Short-term accrual of gray matter pathology in patients with progressive multiple sclerosis: an in vivo study using diffusion tensor MRI. Neuroimage 2005; 24:1139-1146.

127. Droogan AG, Clark CA, Werring DJ, Barker GJ, McDonald WI, Miller DH. Comparison of multiple sclerosis clinical subgroups using navigated spin echo diffusion-weighted imaging. Magn Reson Imaging 1999;17:653-661.

128. Cercignani M, Iannucci G, Rocca MA, Comi G, Horsfield MA, Filippi M. Pathologic damage in MS assessed by diffusionweighted and magnetization transfer MRI. Neurology 2000;54: $1139-1144$

129. Caramia F, Pantano P, Di Legge S, et al. A longitudinal study of MR diffusion changes in normal appearing white matter of patients with early multiple sclerosis. Magn Res Imag 2002;20:383388.

130. Tavazzi E, Dwyer MG, Weinstock-Guttman B, et al. Quantitative diffusion weighted imaging measures in patients with multiple sclerosis. Neuroimage 2007;36:746-754.

131. Bakshi R, Dandamudi VS, Neema M, De C, Bermel RA. Measurement of brain and spinal cord atrophy by magnetic resonance imaging as a tool to monitor multiple sclerosis. J Neuroimaging 2005; $15: 30$ S- 45 S.

132. Bermel RA, Bakshi R. The measurement and clinical relevance of brain atrophy in multiple sclerosis. Lancet Neurol 2006;5:158 170 .

133. Anderson VM, Fox NC, Miller DH. Magnetic resonance imaging measures of brain atrophy in multiple sclerosis. J Magn Reson Imaging 2006;23:605-618.

134. Jasperse B, Minneboo A, de Groot V, et al. Determinants of cerebral atrophy rate at the time of diagnosis of multiple sclerosis. Arch Neurol 2007;64:190-194.

135. Chard DT, Brex PA, Ciccarelli O, et al. The longitudinal relation 
between brain lesion load and atrophy in multiple sclerosis: a 14 year follow up study. J Neurol Neurosurg Psychiatry 2003;74:1551-1554.

136. Bermel RA, Puli SR, Rudick RA, et al. Prediction of longitudinal brain atrophy in multiple sclerosis by gray matter magnetic resonance imaging T2 hypointensity. Arch Neurol 2005;62:13711376.

137. Sanfilipo MP, Benedict RH, Sharma J, et al. The relationship between whole brain volume and disability in multiple sclerosis: a comparison of normalized gray vs. white matter with misclassification correction. Neuroimage 2005;26:1068-1077.

138. Bermel RA, Innus MD, Tjoa CW, Bakshi R. Selective caudate atrophy in multiple sclerosis: a 3D MRI parcellation study. Neuroreport 2003;14:335-339.

139. Carone DA, Benedict RH, Dwyer MG, et al. Semi-automatic brain region extraction (SABRE) reveals superior cortical and deep gray matter atrophy in MS. Neuroimage 2006;29:505-514.

140. Houtchens MK, Benedict RHB, Killiany R, et al. Thalamic atrophy and cognition in multiple sclerosis. Neurology (in press).

141. Dalton CM, Chard DT, Davies GR, et al. Early development of multiple sclerosis is associated with progressive grey matter atrophy in patients presenting with clinically isolated syndromes. Brain 2004;127:1101-1107.

142. Valsasina P, Benedetti B, Rovaris M, et al. Evidence for progressive gray matter loss in patients with relapsing-remitting MS. Neurology 2005;65:1126-1128.

143. Paolillo A, Piattella MC, Pantano P, et al. The relationship between inflammation and atrophy in clinically isolated syndromes suggestive of multiple sclerosis: a monthly MRI study after tripledose gadolinium-DTPA. J Neurol 2004;251:432-439.

144. Rudick RA. Impact of disease-modifying therapies on brain and spinal cord atrophy in multiple sclerosis. J Neuroimaging 2004; 14:54S-64S.

145. Zivadinov R, Locatelli L, Cookfair D, et al. Interferon beta-1a slows progression of brain atrophy in relapsing-remitting multiple sclerosis predominantly by reducing gray matter atrophy. Mult Scler 2007;13:490-501.

146. Miller DH, Soon D, Fernando KT, et al. MRI outcomes in a placebo-controlled trial of natalizumab in relapsing MS. Neurology 2007;68:1390-1401.

147. Chen JT, Collins DL, Atkins HL, et al. Brain atrophy after immunoablation and stem cell transplantation in multiple sclerosis. Neurology 2006;66:1935-1937.

148. Roccatagliata L, Rocca MA, Valsasina P, et al. The long-term effect of AHSCT on MRI measures of MS evolution: a five-year follow-up study. Mult Scler 2007 Apr 27; [Epub ahead of print].

149. Sicotte NL, Giesser BS, Tandon V, et al. Testosterone treatment in multiple sclerosis: a pilot study. Arch Neurol 2007;64:683688.

150. Fox RJ, Fisher E, Tkach J, Lee JC, Cohen JA, Rudick RA. Brain atrophy and magnetization transfer ratio following methylprednisolone in multiple sclerosis: short-term changes and long-term implications. Mult Scler 2005;11:140-145.

151. Neema M, Stankiewicz J, Arora A, et al. T1- and T2-based MRI measures of diffuse gray matter and white matter damage in patients with multiple sclerosis. J Neuroimaging 2007;17:16S$21 \mathrm{~S}$.

152. Vrenken H, Geurts JJ, Knol DL, et al. Whole-brain T1 mapping in multiple sclerosis: global changes of normal-appearing gray and white matter. Radiology 2006;240:811-820.

153. Vrenken H, Rombouts SA, Pouwels PJ, et al. Voxel-based analysis of quantitative T1 maps demonstrates that multiple sclerosis acts throughout the normal-appearing white matter. AJNR Am J Neuroradiol 2006;27:868-874.

154. Vaithianathar L, Tench CR, Morgan PS, et al. White matter T(1) relaxation time histograms and cerebral atrophy in multiple sclerosis. J Neurol Sci 2002;197:45-50.

155. Vaithianathar L, Tench CR, Morgan PS, et al. Magnetic resonance imaging of the cervical spinal cord in multiple sclerosis-a quantitative T1 relaxation time mapping approach. J Neurol 2003; 250:307-315.

156. Parry A, Clare S, Jenkinson M, Smith S, Palace J, Matthews PM. White matter and lesion $\mathrm{T} 1$ relaxation times increase in parallel and correlate with disability in multiple sclerosis. J Neurol 2002;249:1279-1286.

157. Parry A, Clare S, Jenkinson M, Smith S, Palace J, Matthews PM. MRI brain T1 relaxation time changes in MS patients increase over time in both the white matter and the cortex. J Neuroimaging 2003;13:234-239.

158. Niepel G, Tench CR, Morgan PS, Evangelou N, Auer DP, Constantinescu CS. Deep gray matter and fatigue in MS: A T1 relaxation time study. J Neurol 2006;253:896-902.

159. Griffin CM, Dehmeshki J, Chard DT, et al. T1 histograms of normal-appearing brain tissue are abnormal in early relapsingremitting multiple sclerosis. Mult Scler 2002;8:211-216.

160. Castriota-Scanderbeg A, Fasano F, Filippi M, Caltagirone C. T1 relaxation maps allow differentiation between pathologic tissue subsets in relapsing-remitting and secondary progressive multiple sclerosis. Mult Scler 2004;10:556-561.

161. Davies GR, Hadjiprocopis A, Altmann DR, et al. Normal-appearing grey and white matter T1 abnormality in early relapsingremitting multiple sclerosis: a longitudinal study. Mult Scler 2007;13:169-177.

162. Janardhan V, Suri S, Bakshi R. Multiple sclerosis: hyperintense lesions in the brain on nonenhanced T1-weighted MR images evidenced as areas of T1 shortening. Radiology 2007;244:823831.

163. Stankiewicz J, Panter SS, Neema M, et al. Iron in chronic brain disorders: imaging and neurotherapeutic implications. Neurotherapeutics 2007;4:371-386.

164. Brass SD, Chen N, Mulkern R, Bakshi R. Magnetic resonance imaging of iron deposition in neurologic disorders. Top Magn Reson Imaging 2006;17:31-40.

165. Brass SD, Benedict RH, Weinstock-Guttman B, Munschauer F, Bakshi R. Cognitive impairment is associated with subcortical magnetic resonance imaging grey matter $\mathrm{T} 2$ hypointensity in multiple sclerosis. Mult Scler 2006;12:437-444.

166. Bakshi R, Benedict RH, Bermel RA, et al. T2 hypointensity in the deep gray matter of patients with multiple sclerosis: a quantitative magnetic resonance imaging study. Arch Neurol 2002;59:62-68.

167. Tjoa CW, Benedict RH, Weinstock-Guttman B, et al. MRI T2 hypointensity of the dentate nucleus is related to ambulatory impairment in multiple sclerosis. J Neurol Sci 2005;234:17-24.

168. Zhang Y, Zabad RK, Wei X, et al. Deep gray matter 'black T2' on 3 tesla magnetic resonance imaging correlates with disability in multiple sclerosis. Mult Scler 2007 Apr 27[Epub ahead of print].

169. Laule C, Vavasour IM, Kolind SH, et al. Magnetic resonance imaging of myelin. Neurotherapeutics 2007;4:460-484.

170. Laule C, Vavasour IM, Moore GRW, et al. Water content and myelin water fraction in multiple sclerosis: a $\mathrm{T} 2$ relaxation study. J Neurol 2004;251:284-293.

171. Laule C, Leung E, Li DKB, et al. Myelin water imaging in multiple sclerosis: quantitative correlations with histopathology. Mult Scler 2006;12:747-753.

172. MacKay A, Whittall K, Adler J, Li D, Paty D, Graeb D. In vivo visualization of myelin water in brain by magnetic resonance. Magn Reson Med 1994;31:673-677.

173. Moore GR, Leung E, MacKay AL, et al. A pathology-MRI study of the short-T2 component in formalin-fixed multiple sclerosis brain. Neurology 2000;55:1506-1510.

174. Oh J, Han ET, Lee MC, Nelson SJ, Pelletier D. Multislice brain myelin water fractions at $3 \mathrm{~T}$ in multiple sclerosis. J Neuroimaging 2007;17:156-163.

175. Ikuta F, Zimmerman HM. Distribution of plaques in seventy autopsy cases of multiple sclerosis in the United States. Neurology 1976;26:26-28.

176. Dalton CM, Brex PA, Miszkiel KA, et al. Spinal cord MRI in clinically isolated optic neuritis. J Neurol Neurosurg Psychiatry 2003;74:1577-1580.

177. Gilmore CP, Bo L, Owens T, Lowe J, Esiri MM, Evangelou N. Spinal cord gray matter demyelination in multiple sclerosis-a novel pattern of residual plaque morphology. Brain Pathol 2006; 16:202-208

178. Tench CR, Morgan PS, Jaspan T, et al. Spinal cord imaging in multiple sclerosis. J Neuroimaging 2005;15:94S-102S. 
179. Nijeholt GJ, van Walderveen MA, Castelijns JA, et al. Brain and spinal cord abnormalities in multiple sclerosis. Correlation between MRI parameters, clinical subtypes and symptoms. Brain 1998;121:687-697.

180. Losseff NA, Webb SL, O'Riordan JI, et al. Spinal cord atrophy and disability in multiple sclerosis: a new reproducible and sensitive MRI method with potential to monitor disease progression. Brain 1996;119:701-708.

181. Carbonell-Caballero J, Manjon JV, Marti-Bonmati L, et al. Accurate quantification methods to evaluate cervical cord atrophy in multiple sclerosis patients. MAGMA 2006;19:237-246.

182. Maier SE. Examination of spinal cord tissue architecture with magnetic resonance diffusion tensor imaging. Neurotherapeutics 2007;4:453-459.

183. Agosta F, Absinta M, Sormani MP, et al. In vivo assessment of cervical cord damage in MS patients: a longitudinal diffusion tensor MRI study. Brain 2007;130(Pt 8):2211-2219.

184. Ohgiya Y, Oka M, Hiwatashi A, et al. Diffusion tensor MR imaging of the cervical spinal cord in patients with multiple sclerosis. Eur Radiol 2007 May 16; [Epub ahead of print].

185. Hesseltine SM, Law M, Babb J, et al. Diffusion tensor imaging in multiple sclerosis: assessment of regional differences in the axial plane within normal-appearing cervical spinal cord. AJNR Am J Neuroradiol 2006;27:1189-1193.

186. Kendi AT, Tan FU, Kendi M, et al. MR spectroscopy of cervical spinal cord in patients with multiple sclerosis. Neuroradiology 2004;46:764-769.

187. Marliani AF, Clementi V, Albini-Riccioli L, Agati R, Leonardi M. Quantitative proton magnetic resonance spectroscopy of the human cervical spinal cord at 3 Tesla. Magn Reson Med 2007; 57:160-163.

188. Filippi M, Bozzali M, Horsfield MA, et al. A conventional and magnetization transfer MRI study of the cervical cord in patients with MS. Neurology 2000;54:207-213.
189. Rovaris M, Gallo A, Riva R, et al. An MT MRI study of the cervical cord in clinically isolated syndromes suggestive of MS. Neurology 2004;63:584-585.

190. Keiper MD, Grossman RI, Hirsch JA, et al. MR identification of white matter abnormalities in multiple sclerosis: A comparison between $1.5 \mathrm{~T}$ and $4 \mathrm{~T}$. AJNR Am J Neuroradiology 1998;19: $1489-1493$

191. Kangarlu A, Bourekas EC, Ray-Chaudhury A, Rammohan KW. Cerebral cortical lesions in multiple sclerosis detected by MR imaging at 8 Tesla. AJNR Am J Neuroradiol 2007;28:262-266.

192. Sicotte NL, Voskuhl RR, Bouvier S, et al. Comparison of multiple sclerosis lesions at 1.5 and 3.0 Tesla. Invest Radiol 2003; 38:423-427.

193. Wattjes MP, Harzheim M, Kuhl CK, et al. Does high-field MR imaging have an influence on the classification of patients with clinically isolated syndromes according to current diagnostic MR imaging criteria for multiple sclerosis? AJNR Am J Neuroradiol 2006;27:1794-1798.

194. Wattjes MP, Lutterbey GG, Harzheim M, et al. Higher sensitivity in the detection of inflammatory brain lesions in patients with clinically isolated syndromes suggestive of multiple sclerosis using high field MRI: an intraindividual comparison of $1.5 \mathrm{~T}$ with 3.0 T. Eur Radiol 2006;16:2067-2073.

195. Bachmann R, Reilmann R, Schwindt W, Kugel H, Heindel W, Krämer S. FLAIR imaging for multiple sclerosis: a comparative MR study at 1.5 and 3.0 Tesla. Eur Radiol 2006;16:915-921.

196. Smith SA, Farrell JA, Jones CK, et al. Pulsed magnetization transfer imaging with body coil transmission at 3 Tesla: feasibility and application. Magn Reson Med 2006;56:866-875.

197. Weintraub MI, Khoury A, Cole SP. Biologic effects of 3 Tesla (T) MR imaging comparing traditional $1.5 \mathrm{~T}$ and $0.6 \mathrm{~T}$ in 1023 consecutive outpatients. J Neuroimaging 2007;17:241-245. 